\title{
2D MXenes as Co-catalysts in Photocatalysis: Synthetic Methods
}

Cite as

Nano-Micro Lett.

(2019) 11:79

Received: 13 July 2019

Accepted: 25 August 2019

Published online: 21 September 2019

(C) The Author(s) 2019

\author{
Yuliang Sun ${ }^{1,2}$, Xing Meng ${ }^{1,2,3} \bowtie$, Yohan Dall'Agnese ${ }^{4}$, Chunxiang Dall'Agnese ${ }^{1}$, \\ Shengnan Duan ${ }^{1,2}$, Yu Gao ${ }^{1,2}$, Gang Chen ${ }^{1,2}$, Xiao-Feng Wang ${ }^{1,2} \bowtie$ \\ $\triangle$ Xing Meng, mengxing@jlu.edu.cn; Xiao-Feng Wang, xf_wang@jlu.edu.cn \\ 1 Key Laboratory of Physics and Technology for Advanced Batteries (Ministry of Education), College \\ of Physics, Jilin University, Changchun 130012, People's Republic of China \\ 2 Jilin Key Engineering Laboratory of New Energy Materials and Technologies, Jilin University, \\ Changchun 130012, People's Republic of China \\ 3 A. J. Drexel Nanomaterials Institute and Department of Materials Science and Engineering, Drexel \\ University, Philadelphia, PA 19104, USA \\ 4 Institute for Materials Discovery, Faculty of Maths and Physical Sciences, University College London, \\ London WC1E 7JE, UK
}

\section{HIGHLIGHTS}

- Two-dimensional transition metal carbides/nitrides (MXenes) as co-catalysts were summarized and classified according to the different synthesis methods used: mechanical mixing, self-assembly, in situ decoration, and oxidation.

- The working mechanism for MXenes application in photocatalysis was discussed. The improved photocatalytic performance was attributed to enhancement of charge separation and suppression of charge recombination.

ABSTRACT Since their seminal discovery in 2011, two-dimensional (2D) transition metal carbides/nitrides known as MXenes, that constitute a large family of 2D materials, have been targeted toward various applications due to their outstanding electronic properties. MXenes functioning as co-catalyst in combination with certain photocatalysts have been applied in photocatalytic systems to enhance photogenerated charge separation, suppress rapid charge recombination, and convert solar energy into chemical energy or use it in the degradation of organic compounds. The photocatalytic performance greatly depends on the composition and morphology of the photocatalyst, which, in turn, are determined by the method of preparation used. Here, we review the four different synthesis methods (mechanical mixing, self-assembly, in situ decoration, and oxidation) reported for MXenes in view of their application as co-catalyst in photocatalysis. In addition, the working mechanism for MXenes application in photocatalysis is discussed and an outlook for future research is also provided.

KEYWORDS MXenes; Photocatalysis; Co-catalyst; Synthetic methods

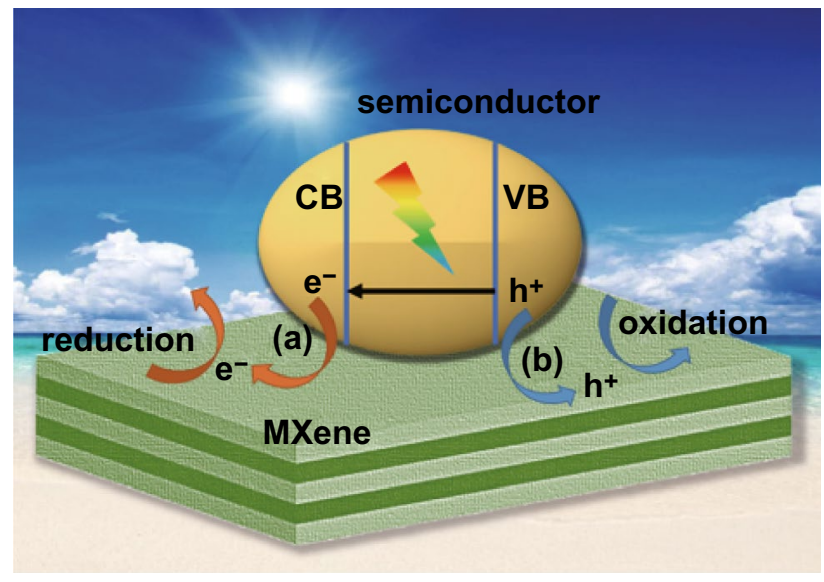




\section{Introduction}

Energy shortage and environmental pollution have become the two major issues faced by humanity due to limited fossil fuel resources and increasing consumption. Developing sustainable and clean energy is the key to addressing these two problems [1-15]. In being clean and inexhaustible, solar energy shows great potential to be one of the most promising future energy sources. Solar energy can be exploited in photovoltaic technologies [16], $\mathrm{CO}_{2}$ photoreduction [17, 18], $\mathrm{N}_{2}$ photo-fixation [19], degradation of organic compounds [20-26], and photocatalytic water splitting [27]. In renewable hydrogen fuel-based photocatalytic water-splitting systems [28-30], photocatalysts play a critical role [31, 32]. Photo-catalyzed solar energy conversion can be divided into three steps: (1) light absorption, (2) charge separation and transfer, and (3) surface reaction. Any improvement on each of these steps will contribute to enhancing the total conversion efficiency. Conventional photocatalysts such as $\mathrm{TiO}_{2}$, g- $\mathrm{C}_{3} \mathrm{~N}_{4}$, and $\mathrm{CdS}$ demonstrate low photocatalytic efficiency due to rapid charge recombination in these materials. Using noble metals such as $\mathrm{Pt}, \mathrm{Ru}$, and $\mathrm{Pd}$ as co-catalysts will increase cost, although such materials can enhance charge separation ability and suppress recombination of charges. A co-catalyst that is both efficient and cheap is thus urgently needed to promote the development of photocatalysis.

MXenes, comprising transition metal carbides, nitrides, and carbonitrides, are a new family of two-dimensional (2D) materials that have attracted much attention in recent years [2]. The general formula of MXene is $\mathrm{M}_{n+1} \mathrm{X}_{n}(n=1,2,3)$, where $\mathrm{M}$ represents a transition metal, such as $\mathrm{Sc}, \mathrm{Ti}, \mathrm{Zr}$, Hf,
$\mathrm{V}, \mathrm{Nb}, \mathrm{Ta}$, and Mo, while $\mathrm{X}$ represents $\mathrm{C}$ and/or N. Owing to their unique structure and superior photoelectronic properties, layered structure MXenes show various potential applications in different areas, such as energy storage [3, 33-38], electromagnetic interference shielding [39, 40], gas sensors [41], wireless communication [42], water treatment [43, 44], solar cells [45-47], and catalysis [41, 48-51]. 2D MXenes are being increasingly studied in the past few years, as evidenced by the rapidly increasing number of scientific articles published per year (Fig. 1a). MXenes are usually synthesized by selectively etching the A layer from MAX phases, which constitute a family of tertiary ductile ceramics, where the A layer is made of an element such as $\mathrm{Al}, \mathrm{Ga}$ [52], or Si [53]. After selective etching of the A layer, 2D MX layers with surface functional groups $(-\mathrm{O},-\mathrm{OH},-\mathrm{F}$, or a mixture of several groups denoted as $\mathrm{T}_{x}$ ) are left. The most widely used methods for selective etching are wet chemical HF etching and in situ HF etching (using a mixture of acids and fluoride salts), although other routes using tetramethylammonium hydroxide (TMAOH) [54, 55], electrochemical [56, 57], or etching with $\mathrm{NaOH}$ [58], and $\mathrm{ZnCl}_{2}$ [49]) have also been explored. Generally, multilayered MXenes are produced by HF etching, whereas single or few-layered MXene flakes are obtained by in situ HF etching or through delamination of a multilayered MXene by intercalation of large organic molecules (Fig. 1b). The etching methods of $\mathrm{Ti}_{3} \mathrm{C}_{2} \mathrm{~T}_{x}$ MXene, which is the first discovered and the most studied MXene, have been reviewed elsewhere $[59,60]$.

In view of the rapid development in the application of 2D MXenes, several reviews on their synthesis [59-61], and application in energy storage $[33,48,62]$ and catalysis
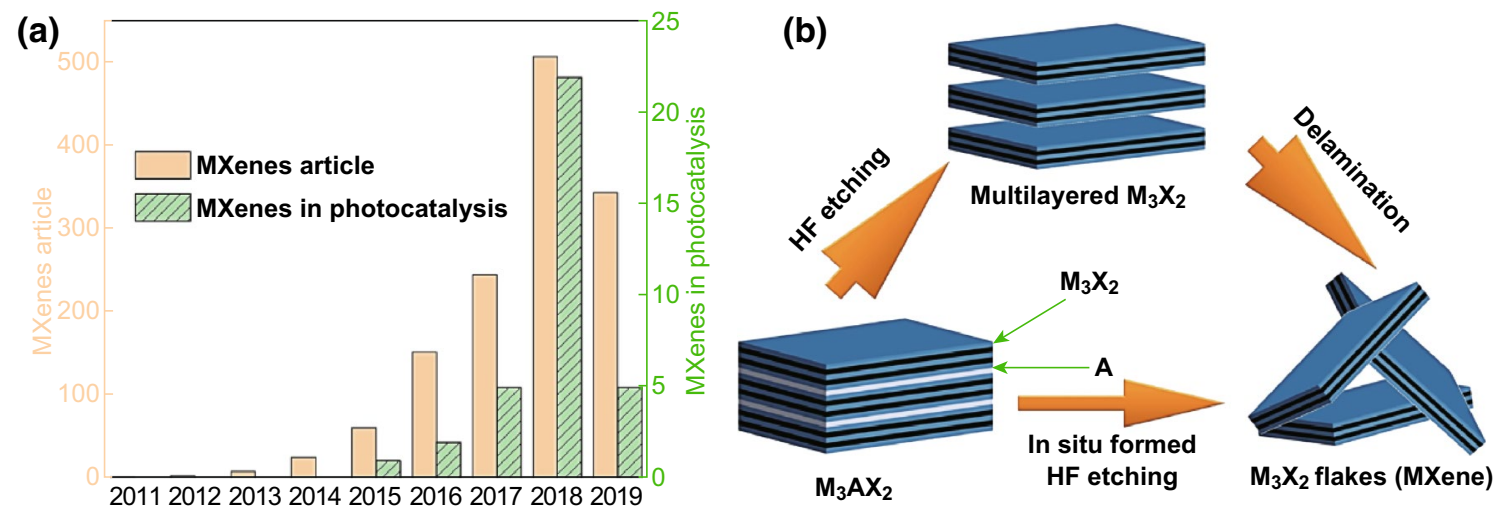

Fig. 1 a The rapid expansion of 2D MXenes materials and $\mathbf{b}$ the most widely used methods to synthesize MXenes 
[51] have been reported. MXenes are promising for application in photocatalysis [63] because of their large surface area, good conductivity, presence of a sufficient number of active sites, and containing suitable elements for effective photocatalysis, but they cannot be directly used as photocatalysts since MXenes are generally not semiconductors [51, 62]. Although there are some MXene semiconductors that have been predicted theoretically [64-68], these have not yet been experimentally synthesized. In this review, we give a detailed discussion on MXene as a co-catalyst in photocatalysis and describe the different methods used for the synthesis of MXene-derived photocatalysts, along with problems encountered in this system and a prospective outlook on future research in this field.

\section{Synthetic Methods for MXenes as Co-catalysts in Photocatalysis}

In view of their good conductivity and large surface area, MXenes have been applied in photocatalysis both to replace noble metal co-catalysts and to enhance the charge separation ability of the photocatalyst (Fig. 2). The most common methods used for the preparation of photocatalyst composites include mechanical mixing, self-assembly, in situ decoration and oxidation, or a combination of the three methods.

\subsection{Mechanical Mixing and Self-assembly}

Mechanical mixing is the easiest method to form photocatalyst composites. Stirring the two components in the liquid phase or grinding of powders can be used for sample preparation. Interestingly, due to electrostatic attraction, photocatalysts with positive charge are easily combined with MXenes whose surfaces are enriched with negative charges, leading to self-assembled photocatalyst composites. In addition, the self-assembling property could be further improved by using other induced techniques simultaneously, where the photocatalysts and co-catalysts are prepared in advance [44].

An et al. [72] demonstrated that synergetic effects of $\mathrm{Ti}_{3} \mathrm{C}_{2}$ MXene and $\mathrm{Pt}$ when used as dual co-catalysts enhanced the photoactivity of $\mathrm{g}-\mathrm{C}_{3} \mathrm{~N}_{4}$ for hydrogen evolution (Fig. 3a), where HF-etched exfoliated $\mathrm{Ti}_{3} \mathrm{C}_{2}$ and $\mathrm{g}-\mathrm{C}_{3} \mathrm{~N}_{4}$ were mixed in liquid by stirring followed by photodeposition of $\mathrm{Pt}$ on the composites. The photoactivity of the dual (a)

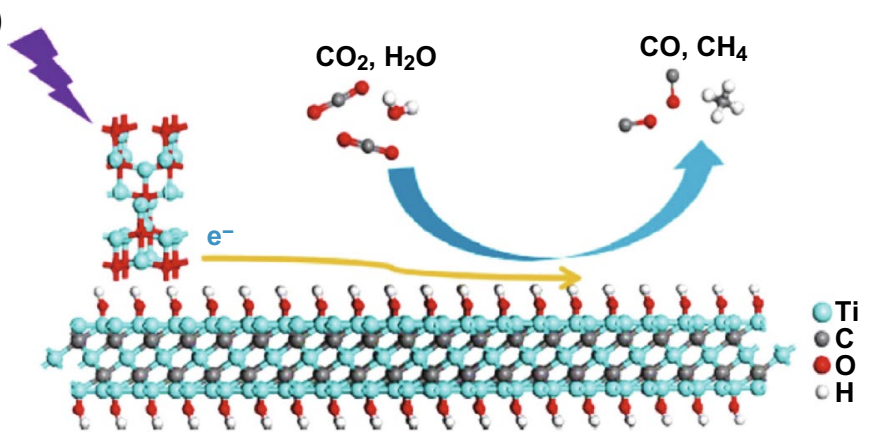

(c)

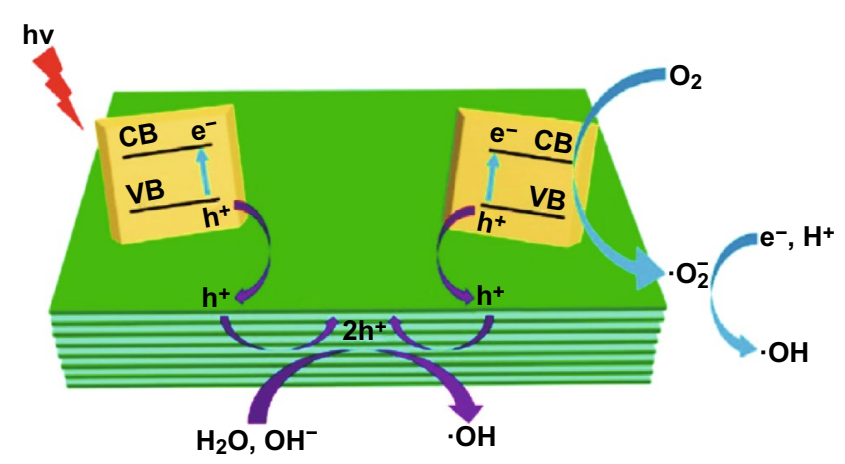

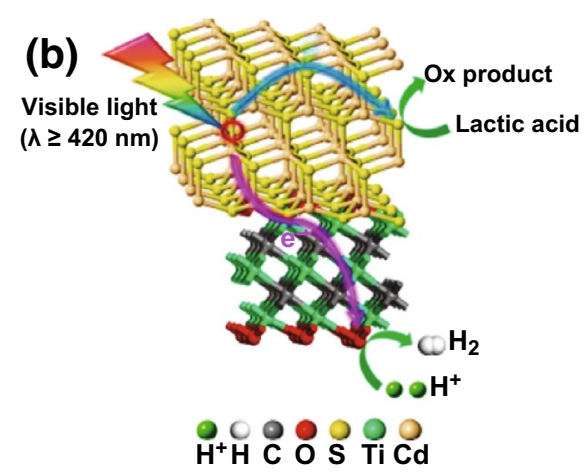

(d)

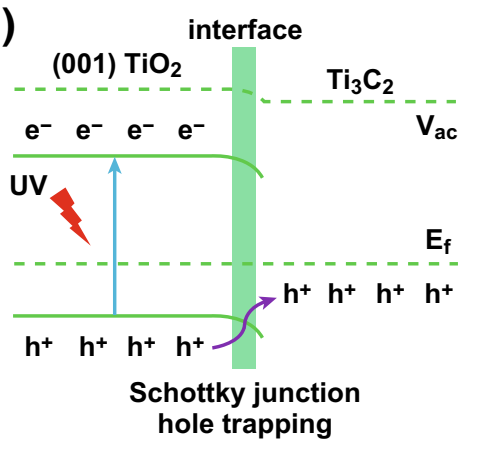

Fig. 2 Schematic showing charge separation between MXene co-catalyst and a photocatalyst taken from a Ye et al. Reprinted with permission from Ref. [69]. Copyright 2018 John Wiley \& Sons. b Ran et al. Reprinted with permission from Ref. [70]. Copyright 2017 Nature Publishing Group. c, d Peng et al. Reprinted with permission from Ref. [71]. Copyright 2016 American Chemical Society 
co-catalysts-modified photocatalysts $\left(\mathrm{g}-\mathrm{C}_{3} \mathrm{~N}_{4} / \mathrm{Ti}_{3} \mathrm{C}_{2} / \mathrm{Pt}\right)$ was much better than that of Pt- or $\mathrm{Ti}_{3} \mathrm{C}_{2}$-only systems, reaching $5.1 \mathrm{mmol} \mathrm{h}^{-1} \mathrm{~g}^{-1}$ in hydrogen production (Fig. 4a). This enhanced performance was due to the presence of $\mathrm{Ti}_{3} \mathrm{C}_{2}$ MXene that facilitated interfacial charge separation and carrier transport from the conduction band (CB) of g- $\mathrm{C}_{3} \mathrm{~N}_{4}$ to Pt. Our group prepared $g-\mathrm{C}_{3} \mathrm{~N}_{4} / \mathrm{Ti}_{3} \mathrm{C}_{2} \mathrm{~T}_{x}$ composites by grinding $\mathrm{g}-\mathrm{C}_{3} \mathrm{~N}_{4}$ and $\mathrm{Ti}_{3} \mathrm{C}_{2} \mathrm{~T}_{x}$ powders together followed by annealing in different gas atmospheres, to tune the surface termination groups (Fig. 4b) [74]. X-ray photoelectron spectroscopy data showed an increase in -O termination groups accompanied by a decrease in $-\mathrm{F}$ termination groups on the surface of $\mathrm{Ti}_{3} \mathrm{C}_{2} . \mathrm{Ti}_{3} \mathrm{C}_{2}$ with $-\mathrm{O}$ termination groups had better photoactivity, revealing that the presence of such groups in $\mathrm{Ti}_{3} \mathrm{C}_{2}$ had a positive effect on hydrogen production by increasing the number of active sites. Moreover, this finding was consistent with density functional theory (DFT) simulation results. The $\left|\Delta G_{\mathrm{H}}\right|$ of $\mathrm{Ti}_{3} \mathrm{C}_{2}$ with $-\mathrm{O}$ terminations was found to be as low as $0.01 \mathrm{eV}$, which is lower than that of
Pt (111). In a similar study, Ye et al. [69] treated HF-etched $\mathrm{Ti}_{3} \mathrm{C}_{2}$ with $\mathrm{KOH}$ to convert $-\mathrm{F}$ groups into $-\mathrm{OH}$ groups, and then combined the $\mathrm{KOH}$-treated $\mathrm{Ti}_{3} \mathrm{C}_{2}$ with $\mathrm{TiO}_{2}(\mathrm{P} 25)$ powder by stirring in water (Fig. 3c). DFT calculations demonstrated that $-\mathrm{OH}$ groups played the role of active sites for the adsorption and activation of $\mathrm{CO}_{2}$ reduction [69]. Experimentally, the photoactivities for $\mathrm{CO}_{2}$ reduction were increased 3 times and 277 times after $\mathrm{KOH}$ treatment, for $\mathrm{CO}$ and $\mathrm{CH}_{4}$, respectively (Fig. 4d). Interestingly, increasing the number of -OH groups not only improved the photo-conversion efficiency but also changed the nature of the products. The $-\mathrm{OH}$ groups resulting from $\mathrm{KOH}$ treatment provided more active sites for $\mathrm{CO}_{2}$ adsorption and enabled greater electron transfer to $\mathrm{CO}_{2}$ and facilitated its reduction to $\mathrm{CH}_{4}$. Though the surface termination groups can be changed through annealing and $\mathrm{KOH}$ treatments, $-\mathrm{F}$ groups could not be completely exchanged. More studies to precisely tailor the termination groups need to be carried out in the future.
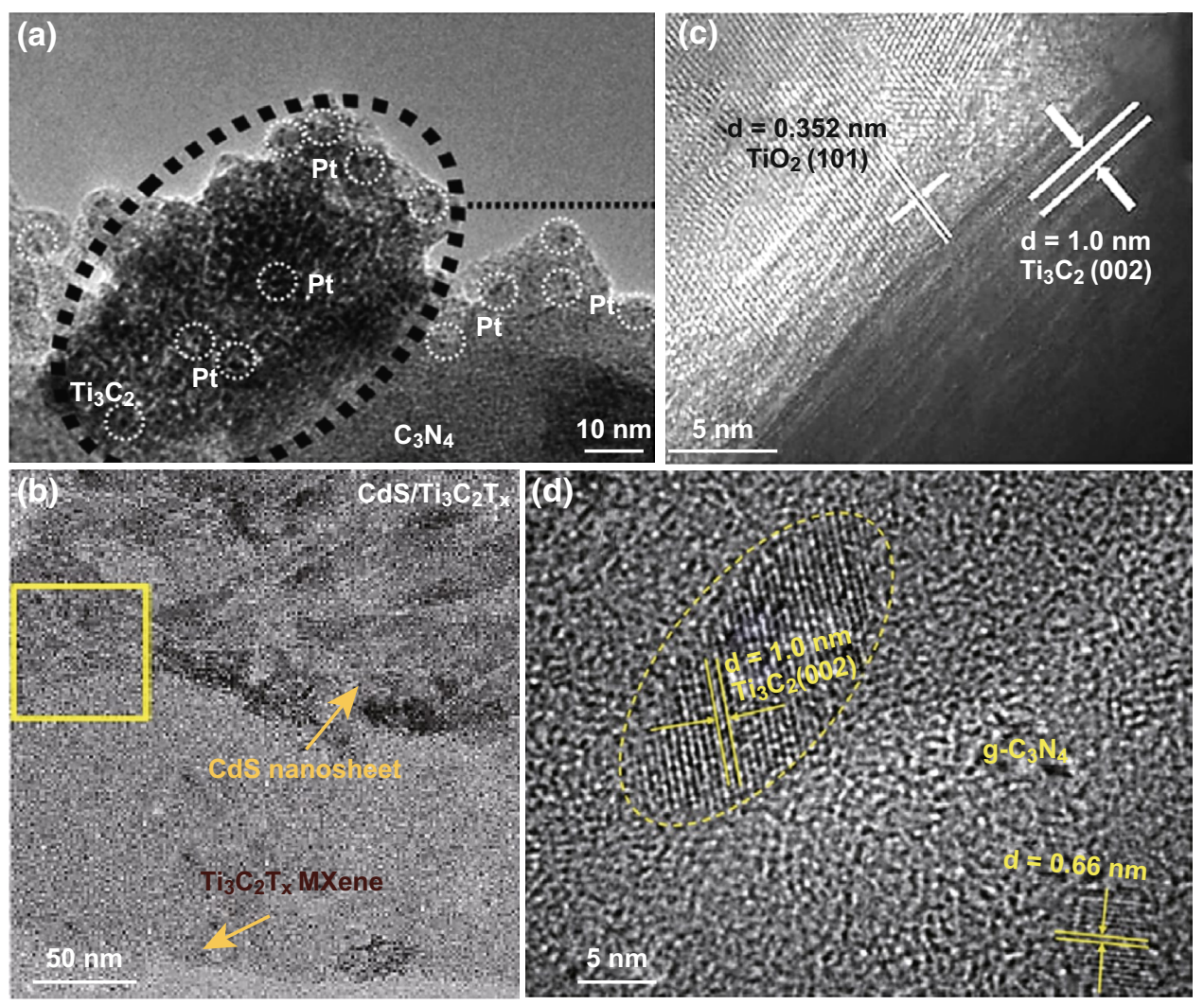

Fig. 3 TEM images of photocatalysts combined with a MXene by mechanical mixing taken from a An et al. Reprinted with permission from Ref. [72]. Copyright 2018 The Royal Society of Chemistry. b Xie et al. Reprinted with permission from Ref. [73]. Copyright 2018 Elsevier. c Ye et al. Reprinted with permission from Ref. [69]. Copyright 2018 John Wiley \& Sons. d Liu et al. Reprinted with permission from Ref. [44]. Copyright 2018 Elsevier 

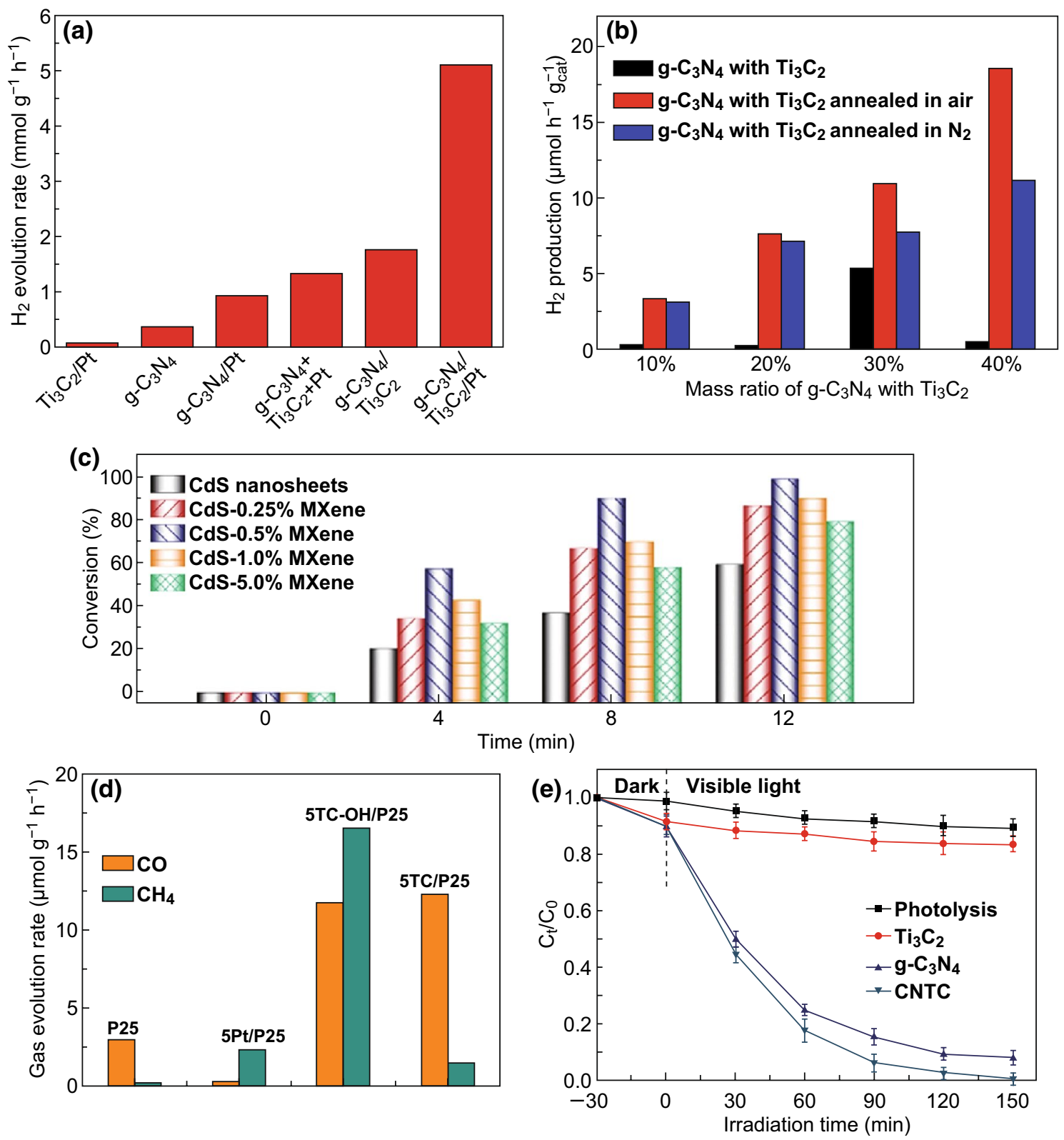

Fig. 4 Hydrogen production of different samples taken from a An et al. Reprinted with permission from Ref. [72]. Copyright 2018 The Royal Society of Chemistry. b Sun et al. Reprinted with permission from Ref. [74]. Copyright 2018 The Royal Society of Chemistry. c Photo-degradation of 4-nitroaniline (4-NA) over different samples from Xie et al. Reprinted with permission from Ref. [73]. Copyright 2018 Elsevier. d Rates of evolution of $\mathrm{CO}$ and $\mathrm{CH}_{4}$ over different samples from Ye et al. Reprinted with permission from Ref. [69]. Copyright 2018 John Wiley \& Sons. e Ciprofloxacin degradation from Liu et al. Reprinted with permission from Ref. [44]. Copyright 2018 Elsevier

Xie et al. [73] used an electrostatic self-assembly process to combine positively charged $\mathrm{CdS}$ nanosheets and $\mathrm{Ti}_{3} \mathrm{C}_{2}$ nanosheets (possessing negative charge) (Fig. 3b) for $\mathrm{CO}_{2}$ reduction (Fig. 4c). Cai et al. [75] synthesized $\mathrm{Ag}_{3} \mathrm{PO}_{4} / \mathrm{Ti}_{3} \mathrm{C}_{2}$ by electrostatically driven self-assembly method, which had the advantage of being a mild method that prevented $\mathrm{Ti}_{3} \mathrm{C}_{2}$ from oxidation. The composites showed better performance than reduced graphene oxide (rGO), and this preparation procedure provided a new direction to the preparation of semiconductor-MXene composites. Liu et al. [44] fabricated a $2 \mathrm{D}$ layered and stacked g- $\mathrm{C}_{3} \mathrm{~N}_{4} / \mathrm{Ti}_{3} \mathrm{C}_{2}$ composite by evaporation-induced self-assembly and used it to degrade 
organic pollutants (ciprofloxacin) (Fig. 3d). Both photogenerated holes and superoxide radicals $\left(\cdot \mathrm{O}_{2}^{-}\right)$resulting from photogenerated electrons played important roles in ciprofloxacin decomposition (Fig. 4f); in this process, self-assembly was an efficient method that allowed intimate mixing of the components in the composite. The sample was also more homogeneous than mechanically mixed ones because of the electrostatic attraction between the charged entities. However, opposite charges on each surface were required for self-assembly, which limited wider application of this process. Therefore, other techniques to induce self-assembly such as evaporation-induced self-assembly were developed to widen the range of application of products [44].

The above-mentioned MXene-based composites prepared by mechanical mixing and self-assembly methods for photocatalysis application are summarized in Table 1. Results from all these works prove that 2D MXene is an efficient additive material to enhance charge separation and charge transfer during photocatalysis. In these two methods, the properties of MXenes are retained by avoiding high temperature and use of other solvents or surfactant. No change in oxidation or surface termination groups occurs in these synthesis methods. Therefore, these two are the easiest and allow synthesis under the mildest conditions.

\subsection{In Situ Decoration of Semiconductors onto the Surface of MXenes}

In contrast to composites prepared by mechanical mixing of materials, in situ decoration methods consist in synthesizing a different material directly onto the MXene surface. As a result, in situ synthetized materials and MXenes are chemically bonded, which could be an important advantage in some designs. However, the range of viable synthetic conditions for in situ decoration is limited, because MXenes are easily oxidized in solution, especially at high temperatures [107]. It is therefore necessary to use mild conditions to protect MXenes from oxidation, especially when monoand few-layered MXenes are used. So far, $\mathrm{g}_{-} \mathrm{C}_{3} \mathrm{~N}_{4}, \mathrm{TiO}_{2}$, $\mathrm{CdS}$, and bismuth compounds have been bonded to various MXenes using this strategy.

g- $\mathrm{C}_{3} \mathrm{~N}_{4}$ is one $2 \mathrm{D}$ semiconductor material that is combined with MXenes used as a co-catalyst in the photocatalysis process (Fig. 5). MXene can be added during the calcination of a precursor, such as melamine and thiourea, but the high calcination temperature (around $550{ }^{\circ} \mathrm{C}$ ) may cause the oxidation of MXene into $\mathrm{TiO}_{2}$. The high photoactivity of g- $\mathrm{C}_{3} \mathrm{~N}_{4} / \mathrm{MXene}$ is attributed to the efficient charge separation; moreover, the heterojunction formed by $\mathrm{TiO}_{2} / \mathrm{g}-\mathrm{C}_{3} \mathrm{~N}_{4}$ also plays an important role in charge separation [108]. Shao et al. [81] synthesized $\mathrm{Ti}_{2} \mathrm{C} / \mathrm{g}-\mathrm{C}_{3} \mathrm{~N}_{4}$ by melamine calcination and used it in hydrogen production (Fig. 5a, d). Though the ratio of $\mathrm{Ti}_{2} \mathrm{C}$ in the composite was as low as $0.4 \mathrm{wt} \%$, a peak due to $\mathrm{TiO}_{2}$ resulting from the oxidation of $\mathrm{Ti}_{2} \mathrm{C}$ could be seen in the XRD pattern. Liu et al. [19] synthesized $\mathrm{TiO}_{2} @ \mathrm{C} / \mathrm{g}-\mathrm{C}_{3} \mathrm{~N}_{4}$ heterojunction by melamine calcination (Fig. 5b), where $\mathrm{Ti}_{3} \mathrm{C}_{2}$ was oxidized to $\mathrm{TiO}_{2} @ \mathrm{C}$ during the calcination process. This composite was highly effective in the reaction of nitrogen reduction to ammonia, with the best performance reaching as high as $250.6 \mu \mathrm{mol} \mathrm{h}^{-1} \mathrm{~g}^{-1}$, which was better than that of $\mathrm{TiO}_{2} @ \mathrm{C}$ and g- $\mathrm{C}_{3} \mathrm{~N}_{4}$ (Fig. 5e). Xu et al. [82] synthesized $\mathrm{Ti}^{3+}$-rich $\mathrm{Ti}_{3} \mathrm{C}_{2} / \mathrm{g}-\mathrm{C}_{3} \mathrm{~N}_{4}$ by calcination of thiourea and employed it as an electrode for $\mathrm{CO}_{2}$ reduction in a photoelectrocatalytic (PEC) system (Fig. 5c, f), achieving a total $\mathrm{CO}_{2}$ reduction rate of $25.1 \mathrm{mmol} \mathrm{h}^{-1} \mathrm{~g}^{-1}$. The $\mathrm{Ti}^{3+}$ species suppressed charge recombination at the $\mathrm{Ti}_{3} \mathrm{C}_{2} / \mathrm{g}-\mathrm{C}_{3} \mathrm{~N}_{4}$ heterojunctions, leading to a corresponding increase in $\mathrm{CO}_{2}$ conversion efficiency.

Apart from the above-mentioned synthesis methods, composite photocatalysts can also be synthesized by combining $\mathrm{TiO}_{2}$, a metal sulfide, or a bismuthide with MXene under hydrothermal conditions (Fig. 6). Gao et al. [83] synthesized $\mathrm{TiO}_{2} / \mathrm{Ti}_{3} \mathrm{C}_{2}$ nanocomposites by a hydrothermal method using $\mathrm{TiSO}_{4}$ as a precursor for methyl orange (MO) degradation (Fig. 6a), where small $\mathrm{TiO}_{2}$ particles could be observed on the surface of multilayered $\mathrm{Ti}_{3} \mathrm{C}_{2}$. Wang et al. [84] employed $\mathrm{TiCl}_{4}$ as the precursor in the hydrothermal synthesis of rutile $\mathrm{TiO}_{2} / \mathrm{Ti}_{3} \mathrm{C}_{2} \mathrm{~T}_{x}$ for hydrogen production by water splitting (Fig. 6d). The photocatalytic activity of $\mathrm{TiO}_{2}$ when combined with other MXenes $\left(\mathrm{Ti}_{2} \mathrm{CT}_{x}\right.$ and $\mathrm{Nb}_{2} \mathrm{CT}_{x}$ flakes) as co-catalysts was also explored; results proved that in general, MXenes could be used as effective co-catalysts for solar hydrogen production. Ran et al. [70] combined $\mathrm{CdS}$ and $\mathrm{Ti}_{3} \mathrm{C}_{2}$ particles by a one-step hydrothermal reaction (Fig. 6b). A hydrogen production rate of $14,342 \mu \mathrm{mol} \mathrm{h}^{-1} \mathrm{~g}^{-1}$ was achieved when using $\mathrm{Ti}_{3} \mathrm{C}_{2}$ as the co-catalyst; this performance is 136.6 times higher than that of the pure CdS photocatalyst. The effectivity and versatility of $\mathrm{Ti}_{3} \mathrm{C}_{2}$ MXene as a co-catalyst for photocatalytic hydrogen production was demonstrated by other metal sulfides $(\mathrm{ZnS})$ [91] photocatalysts as well. Xie et al. [73] showed that $\mathrm{Ti}_{3} \mathrm{C}_{2}$ 


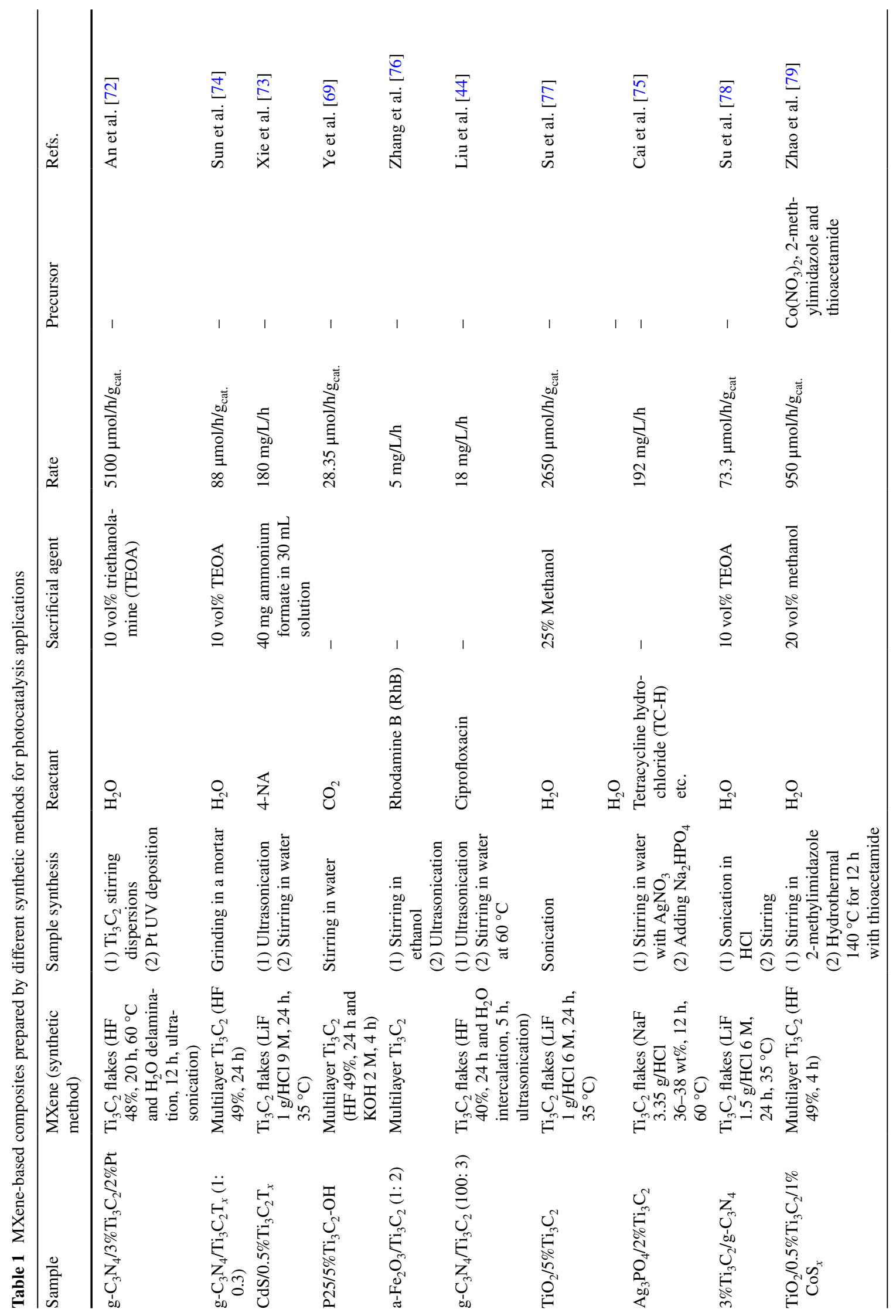




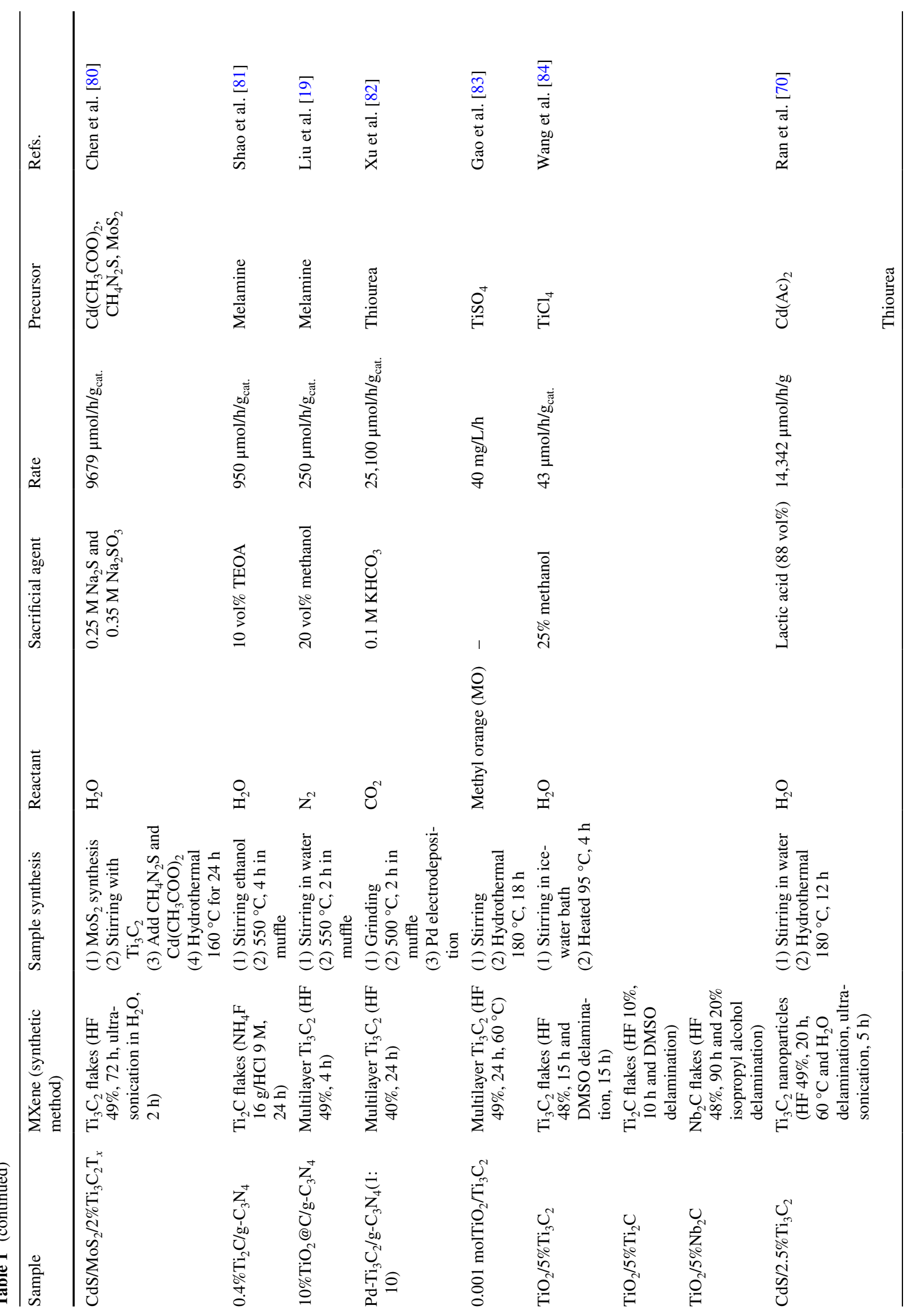




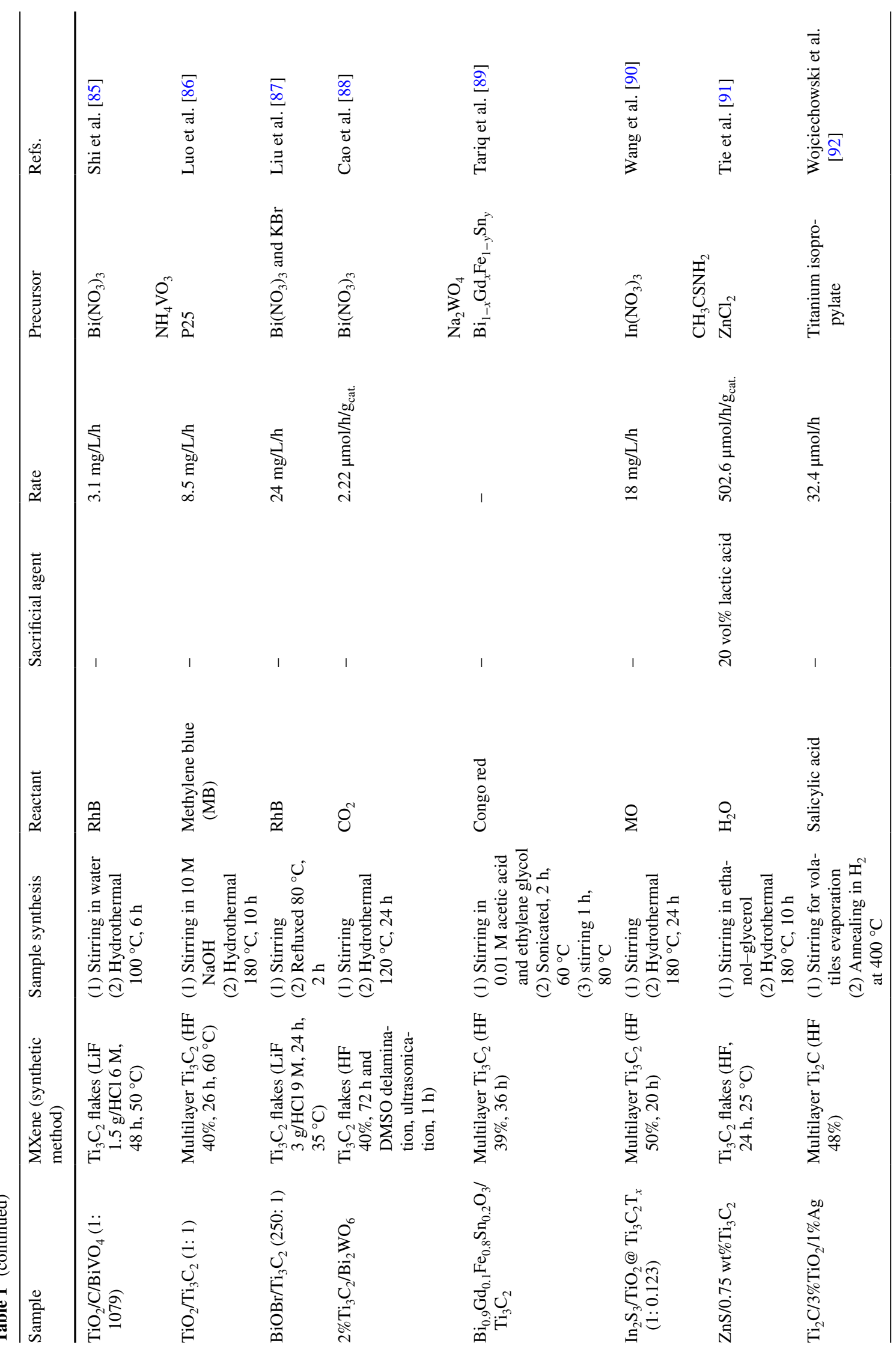




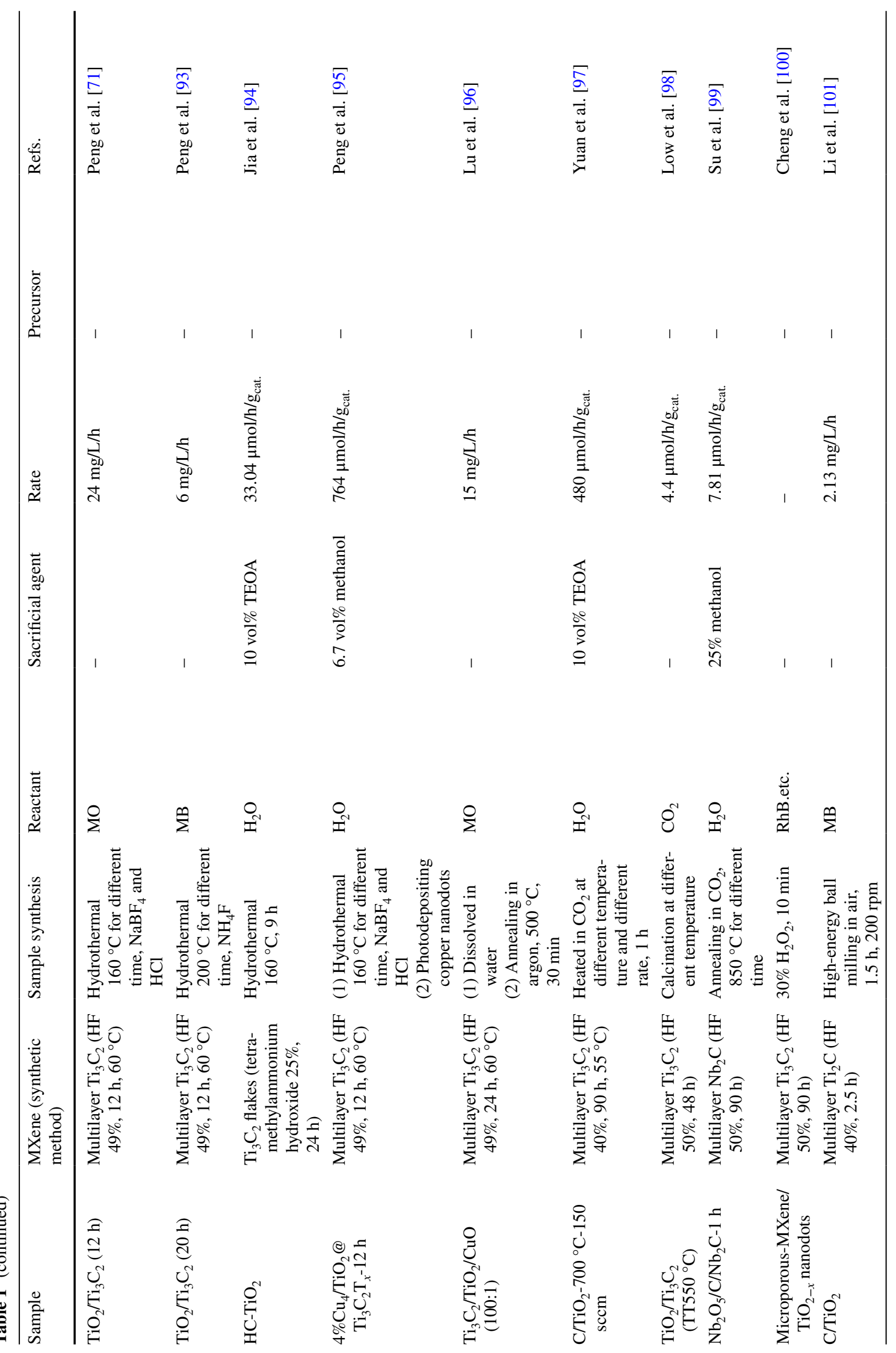




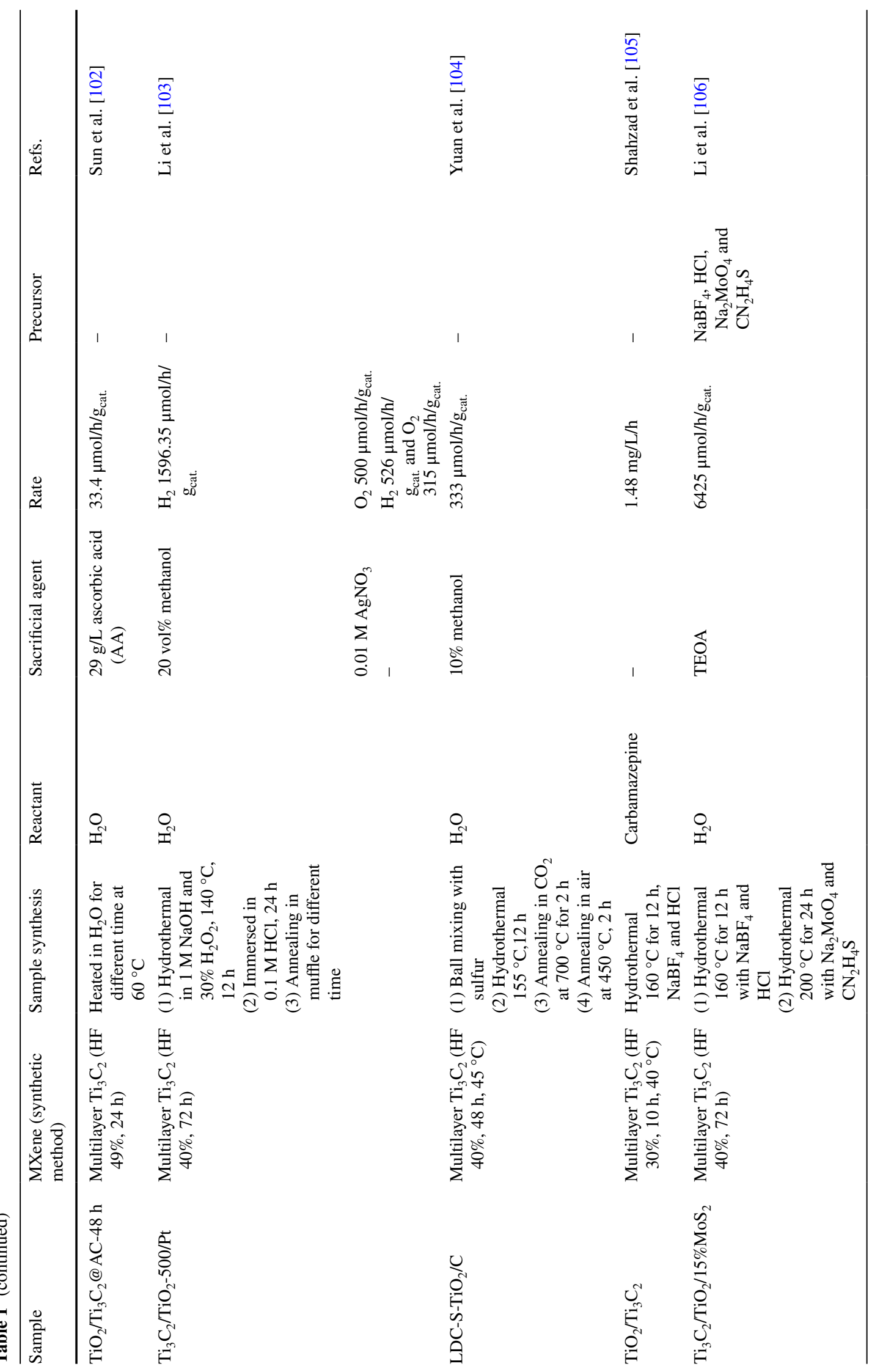



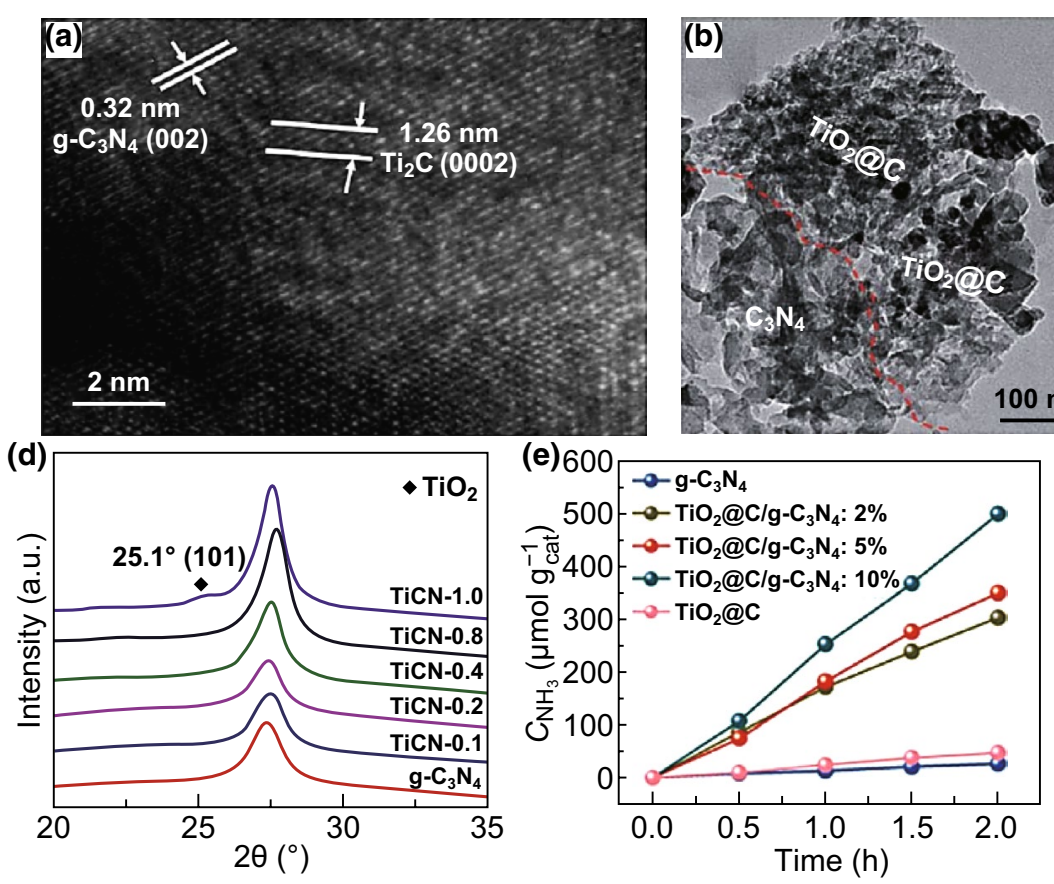
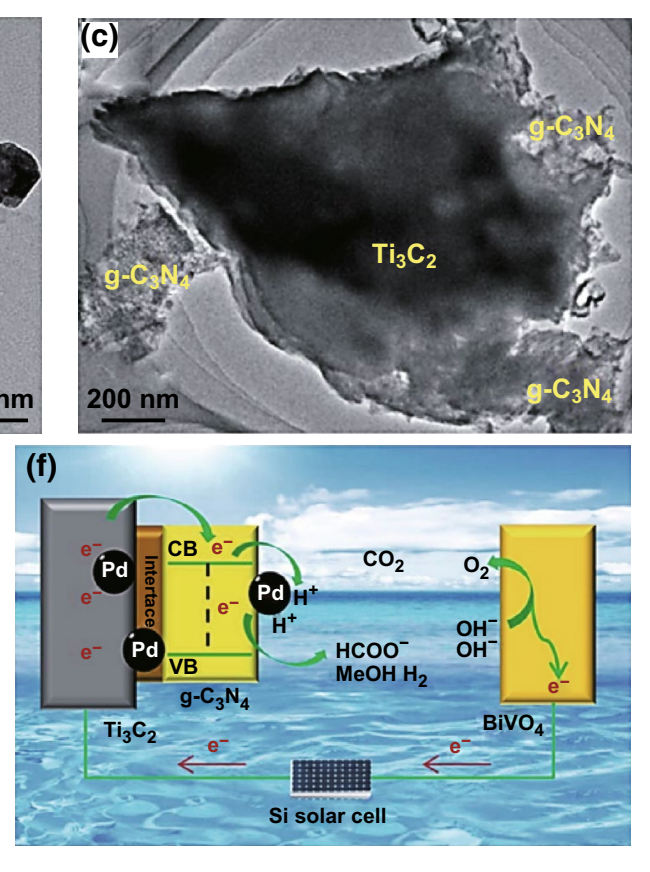

Fig. 5 Photocatalytic composites based on MXene in combination with $\mathrm{g}_{-} \mathrm{C}_{3} \mathrm{~N}_{4}$ formed by in situ decoration. a-c TEM images, $\mathbf{d}$ XRD patterns, e hydrogen production, and $\mathbf{f}$ mechanism for PEC reduction of $\mathrm{CO}_{2}$ from Shao et al. a, $\mathbf{d}$ Reprinted with permission from Ref. [81]. Copyright 2017 The Royal Society of Chemistry; b, e with permission from Ref. [19], Copyright 2018 The Royal Society of Chemistry; and c, f with permission from Ref. [82]. Copyright 2018 The Royal Society of Chemistry

flakes enabled the local confinement of $\mathrm{Cd}^{2+}$ released during photo-corrosion and thus enhanced the stability of the metal sulfide. Besides $\mathrm{CdS}, \operatorname{In}_{2} \mathrm{~S}_{3} / \mathrm{Ti}_{3} \mathrm{C}_{2} \mathrm{~T}_{x}$ hybrids synthesized by hydrothermal method have been used for methyl orange degradation as reported by Wang et al. [90]. Among the hybrids based on other additives (carbon nanotubes (CNT), rGO, $\mathrm{MoS}_{2}$, and $\mathrm{TiO}_{2}$ ), $\mathrm{Ti}_{3} \mathrm{C}_{2}$-based composites showed the best photocatalytic activity, which is attributed to their high electrical conductivity. Shi et al. [85] synthesized $\mathrm{TiO}_{2} / \mathrm{C} /$ $\mathrm{BiVO}_{4}$ composites by hydrothermal method for the degradation of Rhodamine $\mathrm{B}$, where $\mathrm{Ti}_{3} \mathrm{C}_{2}$ was employed both as a support for the growth of $\mathrm{BiVO}_{4}$ nanoparticles and as a precursor for the generation of $2 \mathrm{D}$-carbon upon oxidation. The electron transfer process was accelerated by the presence of $\mathrm{Ti}_{3} \mathrm{C}_{2}$-derived 2D-carbon layers, thus improving the photocatalytic performance for Rhodamine $\mathrm{B}$ degradation. Ultrathin $2 \mathrm{D} / 2 \mathrm{D}$ heterojunction of $\mathrm{MXene} / \mathrm{Bi}_{2} \mathrm{WO}_{6}$ prepared by the in situ growth of ultrathin $\mathrm{Bi}_{2} \mathrm{WO}_{6}$ nanosheets on the surface of ultrathin $\mathrm{Ti}_{3} \mathrm{C}_{2}$ nanosheets for photocatalytic $\mathrm{CO}_{2}$ reduction was reported by Cao et al. [88] (Fig. 6c). The $\mathrm{CH}_{4}$ and $\mathrm{CH}_{3} \mathrm{OH}$ yield were 4.6 times higher than those obtained with pristine $\mathrm{Bi}_{2} \mathrm{WO}_{6}$, which was ascribed to the enhanced $\mathrm{CO}_{2}$ adsorption arising from the increased specific surface area and improved pore structure of the layered heterojunction. The different composites/hybrids containing MXene or MXene-derived products prepared by hydrothermal methods and used in photocatalysis are listed in Table 1.

The synthetic process for MXenes-based composites includes doping into the photocatalysts or using MXene as a support for in situ decoration of the semiconductor photocatalyst. The chemical reactions taking place during photocatalyst formation led to increased interfacial area, thus providing greater possibilities for the transfer of photogenerated electrons. However, one disadvantage of this method is the oxidation of MXenes during photocatalyst synthesis. Although difficult to precisely characterize, conditions of formation of the photocatalysts may be too harsh and cause structural degradation of MXenes, especially in the case of single-layered MXenes, due to their lower stability toward oxidation. 

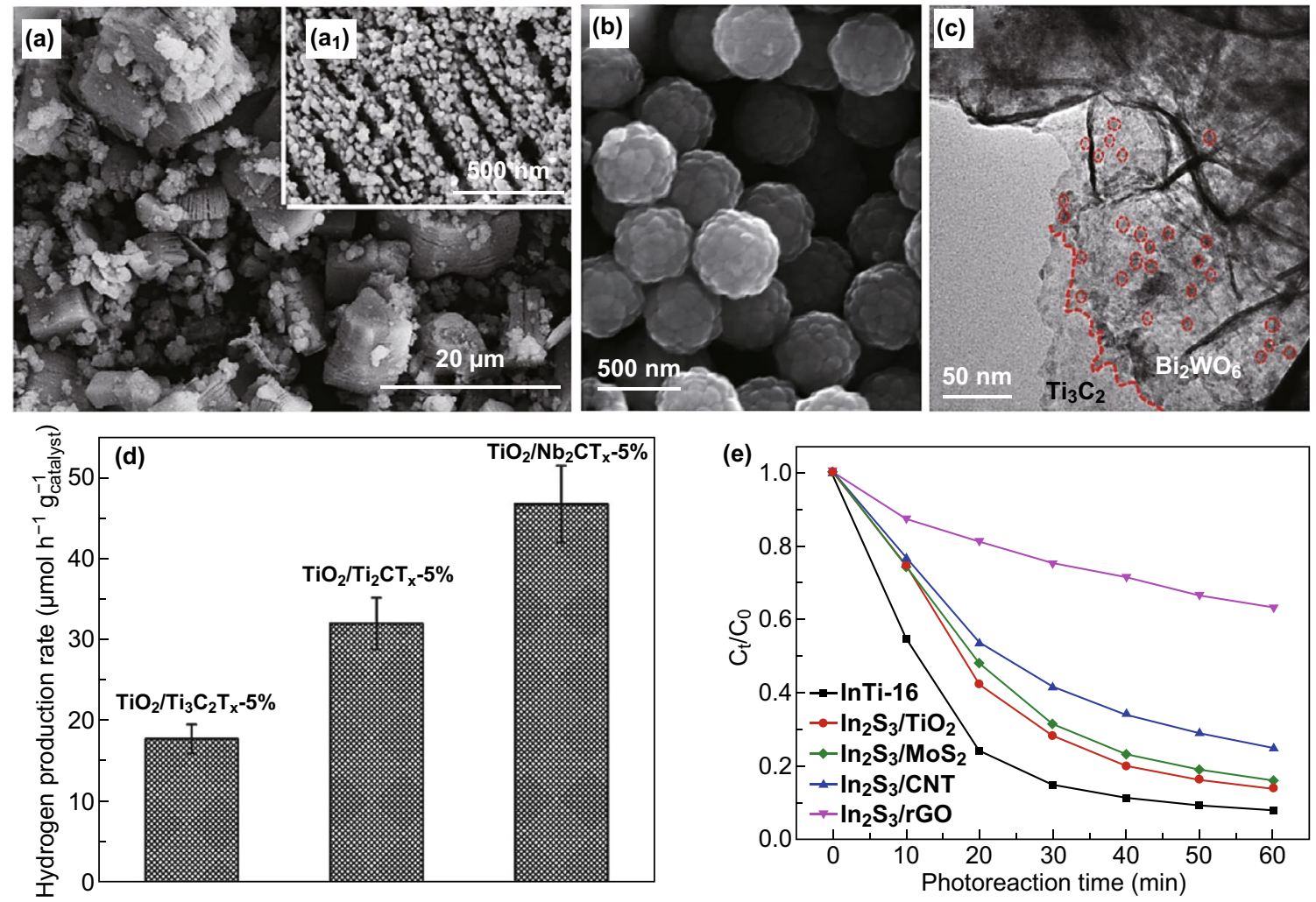

Fig. 6 Photocatalysts based on in situ decoration of MXenes. SEM images from a Gao et al. Reprinted with permission from Ref. [83]. Copyright 2015 Elsevier. b Ran et al. Reprinted with permission from Ref. [70]. Copyright 2017 Nature Publishing Group. c TEM images from Cao et al. Reprinted with permission from Ref. [88]. Copyright 2018 John Wiley \& Sons. d Hydrogen production from Wang et al. Reprinted with permission from Ref. [84]. Copyright 2016 John Wiley \& Sons. e Degradation of methyl orange (MO) from Wang et al. Reprinted with permission from Ref. [90]. Copyright 2018 Elsevier

\subsection{MXene-Derived Photocatalysts}

Different from mechanical mixing, self-assembly, and decoration methods, the in situ oxidation method using MXene $\left(\mathrm{Ti}_{3} \mathrm{C}_{2}\right.$ is the most studied example) as a precursor for the synthesis of photocatalysts has also been explored (Fig. 7). Peng's group tuned the facet of $\mathrm{TiO}_{2} / \mathrm{Ti}_{3} \mathrm{C}_{2}$ using a hydrothermal method without using an additional $\mathrm{TiO}_{2}$ precursor (Fig. 7a, b) [71, 93]. $\mathrm{NaBF}_{4}$ and $\mathrm{NH}_{4} \mathrm{~F}$ were used as reagents to, respectively, control morphology in the synthesis of (001) $\mathrm{TiO}_{2} / \mathrm{Ti}_{3} \mathrm{C}_{2}$ and (111) $\mathrm{TiO}_{2} / \mathrm{Ti}_{3} \mathrm{C}_{2}$, which were then applied in methyl orange degradation. Both the facet type of $\mathrm{TiO}_{2}$ and the ratio of $\mathrm{TiO}_{2}$ to $\mathrm{Ti}_{3} \mathrm{C}_{2}$ could be controlled by changing the duration of the hydrothermal reaction. Jia et al. [94] obtained closely aggregated $\mathrm{TiO}_{2}$ nanorods with high carbon doping starting from $\mathrm{Ti}_{3} \mathrm{C}_{2}$ flakes and demonstrated a better photoactivity than commercially available P25 for hydrogen production (Fig. 7c). The carbon doping also changed the electron structure of $\mathrm{TiO}_{2}$ and enhanced its light absorption ability. Peng et al. [95] also used $\mathrm{Ti}_{3} \mathrm{C}_{2}$ as a hole trap and $\mathrm{Cu}$ as an electron trap to separate the charges through a dual-carrier-separation mechanism, showing the potential of MXene as an efficient functional material for photocatalysis (Fig. 7d).

Calcination under atmosphere containing gases such as $\mathrm{CO}_{2}$ and $\mathrm{O}_{2}$ is another method used for the controlled oxidation of MXenes (Fig. 8). Lu et al. [96] obtained $\mathrm{Ti}_{3} \mathrm{C}_{2} /$ $\mathrm{TiO}_{2} / \mathrm{CuO}$ by annealing $\mathrm{Cu}\left(\mathrm{NO}_{3}\right)_{2}$ and $\mathrm{Ti}_{3} \mathrm{C}_{2}$ together under argon atmosphere (Fig. 8a). Because of its good electronic conductivity, the incorporation of $\mathrm{Ti}_{3} \mathrm{C}_{2}$ improved electron/ hole separation and led to better methyl orange degradation. Yuan et al. [97] annealed $\mathrm{Ti}_{3} \mathrm{C}_{2}$ in $\mathrm{CO}_{2}$ to prepare 2D-layered $\mathrm{C} / \mathrm{TiO}_{2}$ hybrids used in hydrogen production, in which the presence of $2 \mathrm{D}$ carbon layers increased electron transport channels and enhanced charge separation efficiency (Fig. 8b). In addition, the effects of oxidation temperature 

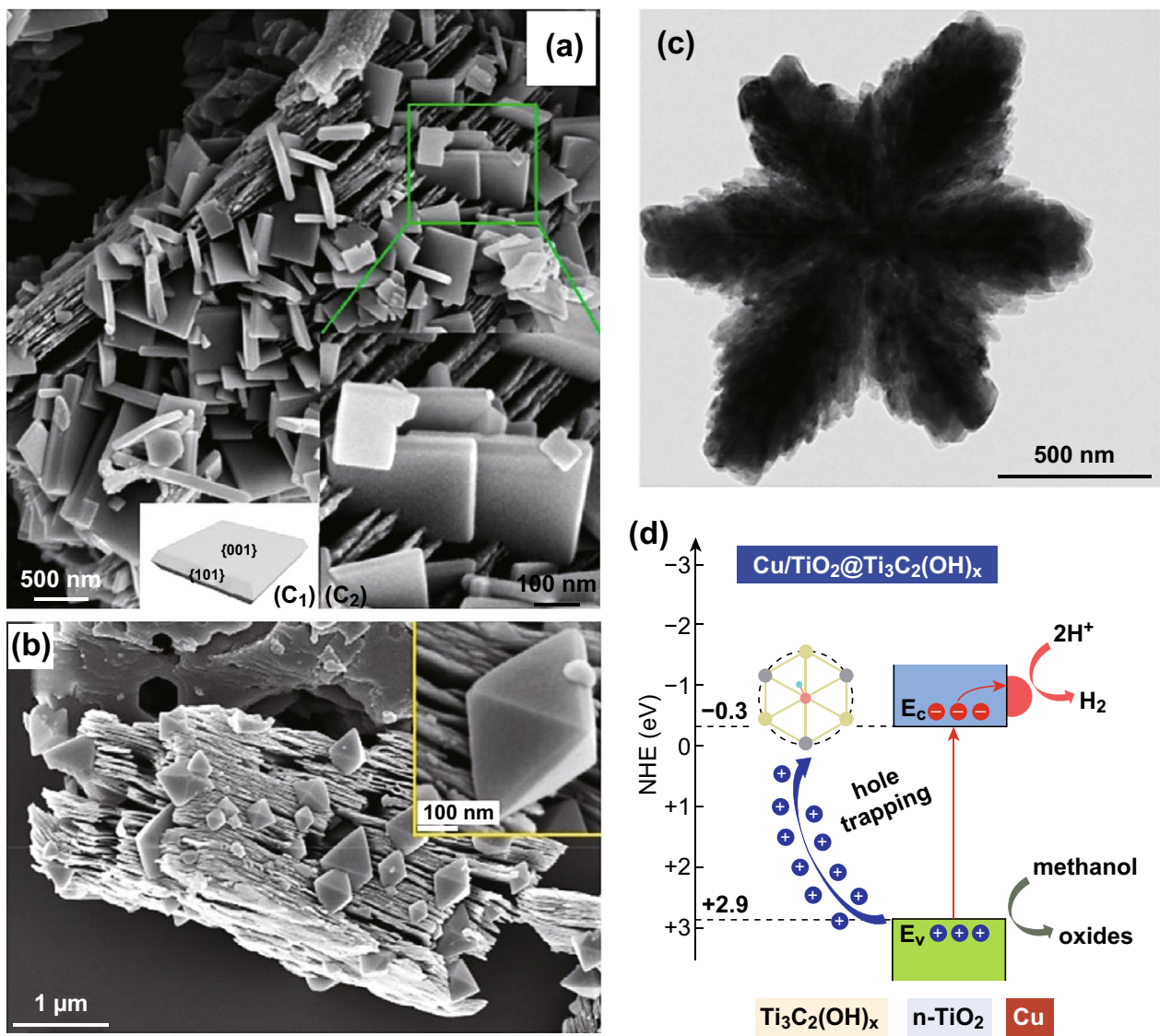

Fig. 7 In situ oxidized MXenes by hydrothermal method for photocatalysis. SEM images taken from a Peng et al. Reprinted with permission from Ref. [71]. Copyright 2016 American Chemical Society. b Peng et al. Reprinted with permission from Ref. [93]. Copyright 2017 Elsevier. c TEM image from Jia et al. Reprinted with permission from Ref. [94]. Copyright 2018 American Chemical Society. d Charge transfer in Cu/ $\mathrm{TiO}_{2} @ \mathrm{Ti}_{3} \mathrm{C}_{2}(\mathrm{OH})_{x}$ from Peng et al. Reprinted with permission from Ref. [95]. Copyright 2018 Elsevier

and $\mathrm{CO}_{2}$ on the grain size and crystal structure of $\mathrm{TiO}_{2}$ were also investigated, revealing that increasing oxidation temperature and $\mathrm{CO}_{2}$ gas flux led to larger grain sizes and more rutile $\mathrm{TiO}_{2}$ formation. Low et al. [98] calcined $\mathrm{Ti}_{3} \mathrm{C}_{2}$ at different temperatures, enabling the in situ growth of $\mathrm{TiO}_{2}$ nanoparticles on $\mathrm{Ti}_{3} \mathrm{C}_{2}$ nanosheets, thus forming $\mathrm{TiO}_{2} / \mathrm{Ti}_{3} \mathrm{C}_{2}$ composites with different loading amounts of $\mathrm{TiO}_{2}$ with the aim to improve performance in $\mathrm{CO}_{2}$ reduction reaction (Fig. 8c). Interestingly, three main products were obtained during the photocatalytic $\mathrm{CO}_{2}$ reduction process due to the sufficiently high intrinsic reduction potential of $\mathrm{TiO}_{2}$. Results of the study also pointed out that excess of $\mathrm{Ti}_{3} \mathrm{C}_{2}$ in the composite could have an adverse effect on photocatalytic performance. Su et al. [99] used $\mathrm{CO}_{2}$ to partially oxidize $\mathrm{Nb}_{2} \mathrm{C}$ to form $\mathrm{Nb}_{2} \mathrm{O}_{5} / \mathrm{Nb}_{2} \mathrm{C}$ composites for hydrogen production, where $\mathrm{Nb}_{2} \mathrm{O}_{5}$ and metallic $\mathrm{Nb}_{2} \mathrm{C}$ served, respectively, as the semiconductor photocatalyst and co-catalyst (Fig. 8d).
The easily formed junction at the interface served as an electron sink to efficiently capture photogenerated electrons and suppress recombination of photogenerated electron-hole pairs, thus enhancing the efficiency of charge separation and contributing to improved photocatalytic activity [71, 93, 99, 102].

Besides the hydrothermal method and calcination, other routes such as chemical oxidization and high-energy ball milling were also used to oxidize MXenes (Fig. 9). Cheng et al. [100] oxidized $\mathrm{Ti}_{3} \mathrm{C}_{2}$ flakes with $30 \% \mathrm{H}_{2} \mathrm{O}_{2}$ to form microporous-MXene/TiO ${ }_{2-x}$ nanodots (Fig. 9a). This composite worked as a photo-Fenton bifunctional catalyst for Rhodamine B degradation under both dark and illumination conditions. Li et al. [101] synthesized $\mathrm{TiO}_{2} @ \mathrm{C}$ nanosheets from $\mathrm{Ti}_{2} \mathrm{C}$ by high-energy ball milling and used it for methylene blue degradation (Fig. 9b). Shortly thereafter, our group used water to oxidize $\mathrm{Ti}_{3} \mathrm{C}_{2}$ to be applied in hydrogen 

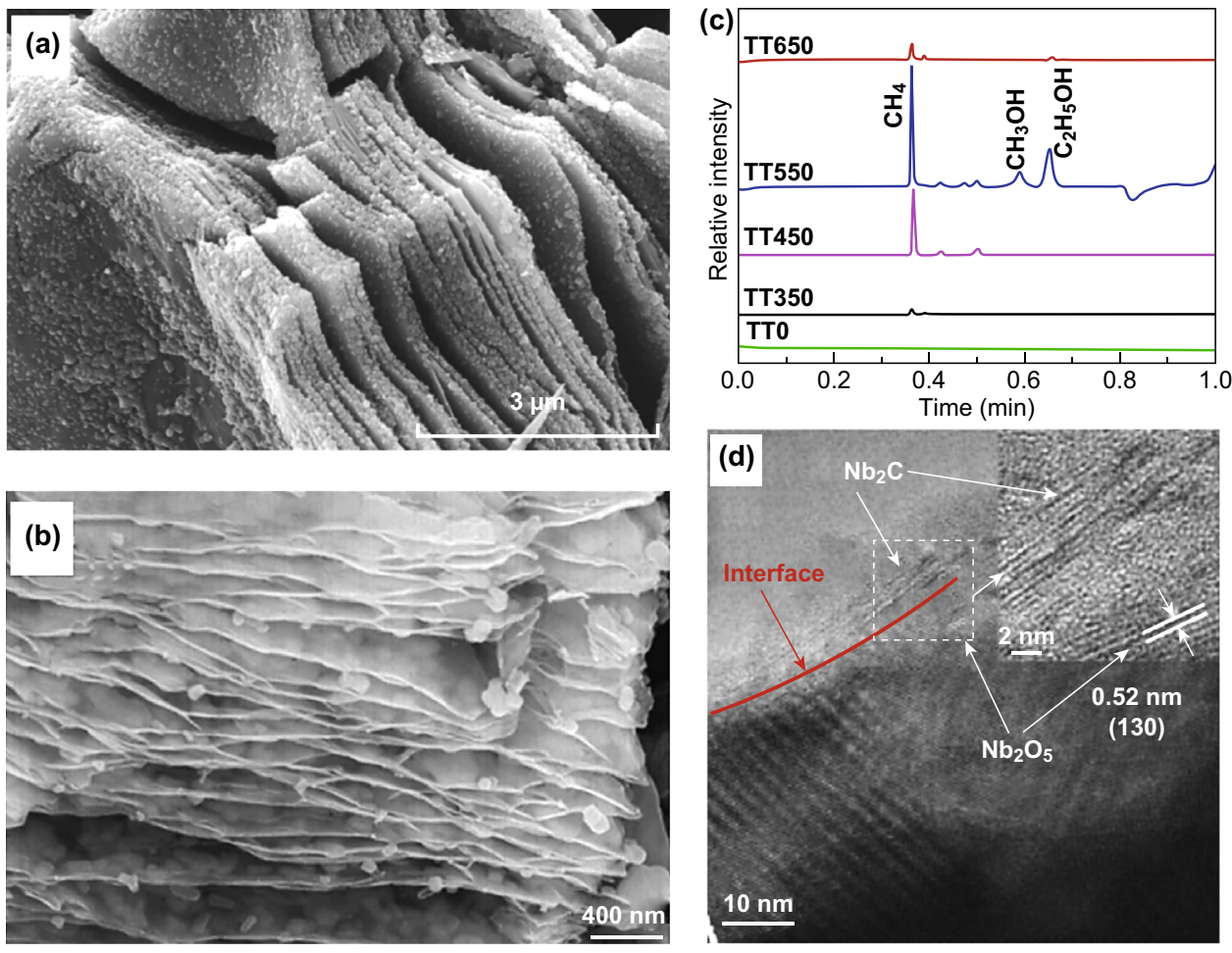

Fig. 8 Photocatalysts containing in situ oxidized MXenes formed by calcination. SEM images from a Lu et al. Reprinted with permission from Ref. [96]. Copyright 2017 Hindawi. b Yuan et al. Reprinted with permission from Ref. [97]. Copyright 2017 John Wiley \& Sons. c Gaseous products of $\mathrm{CO}_{2}$ reduction from Low et al. Reprinted with permission from Ref. [98]. Copyright 2018 Elsevier. d TEM image from Su et al. Reprinted with permission from Ref. [99]. Copyright 2018 John Wiley \& Sons

production using Eosin $\mathrm{Y}$ as a sensitizer [102]. Similar to other oxidized MXenes, amorphous carbon and $\mathrm{TiO}_{2}$ were formed after oxidation (Fig. 9c, d). The various MXenederived composites obtained by in situ oxidation to be used as photocatalysts are listed in Table 1 .

The MXenes oxidation is different from other methods because of the residual presence of carbon (mostly amorphous carbon) after oxidation, and the M element is oxidized into metal oxide on the carbon layer. Thus, the composite obtained is of the form metal oxide/MXenes/C. Both MXenes and $\mathrm{C}$ can be used as co-catalysts in the photocatalysis process. However, in this method, the ratio of the photocatalyst to MXenes varies within a certain range since no precursor is introduced. The limitation of this method is that only a few semiconductors (depending on M element) can be used as the photocatalyst.

\section{Mechanism of MXenes as Co-catalysts}

Since MXenes are conductors and serve as co-catalysts, the mechanism of action of a MXenes-based photocatalytic system is through accelerated charge separation and suppression of carrier recombination [69-71]. The photocatalysts absorb visible light and photogenerated electrons are excited to the $\mathrm{CB}$, while holes are left in the valence band (VB). The excited charge carriers are transferred to MXenes at the interface mainly because of the higher potential of MXenes. Electrons transfer to MXenes without recombination and react on the MXene surface to generate $\mathrm{H}_{2}$ by reducing $\mathrm{H}^{+}$ [74, 78, 81, 91, 94, 102, 103], $\mathrm{CH}_{4}$ and $\mathrm{CO}$ by reducing $\mathrm{CO}_{2}$ $[88,98]$, or $\mathrm{NH}_{3}$ by reducing $\mathrm{N}_{2}$ [19], as shown in Fig. 10 process (a). In process (b), holes transfer to MXenes and react to produce $\mathrm{OH} \cdot$ that can be utilized for degradation of organics [71, 93, 95]; electrons can also produce $\mathrm{OH} \cdot$ for organic degradation $[71,93]$. The charge transfer process 

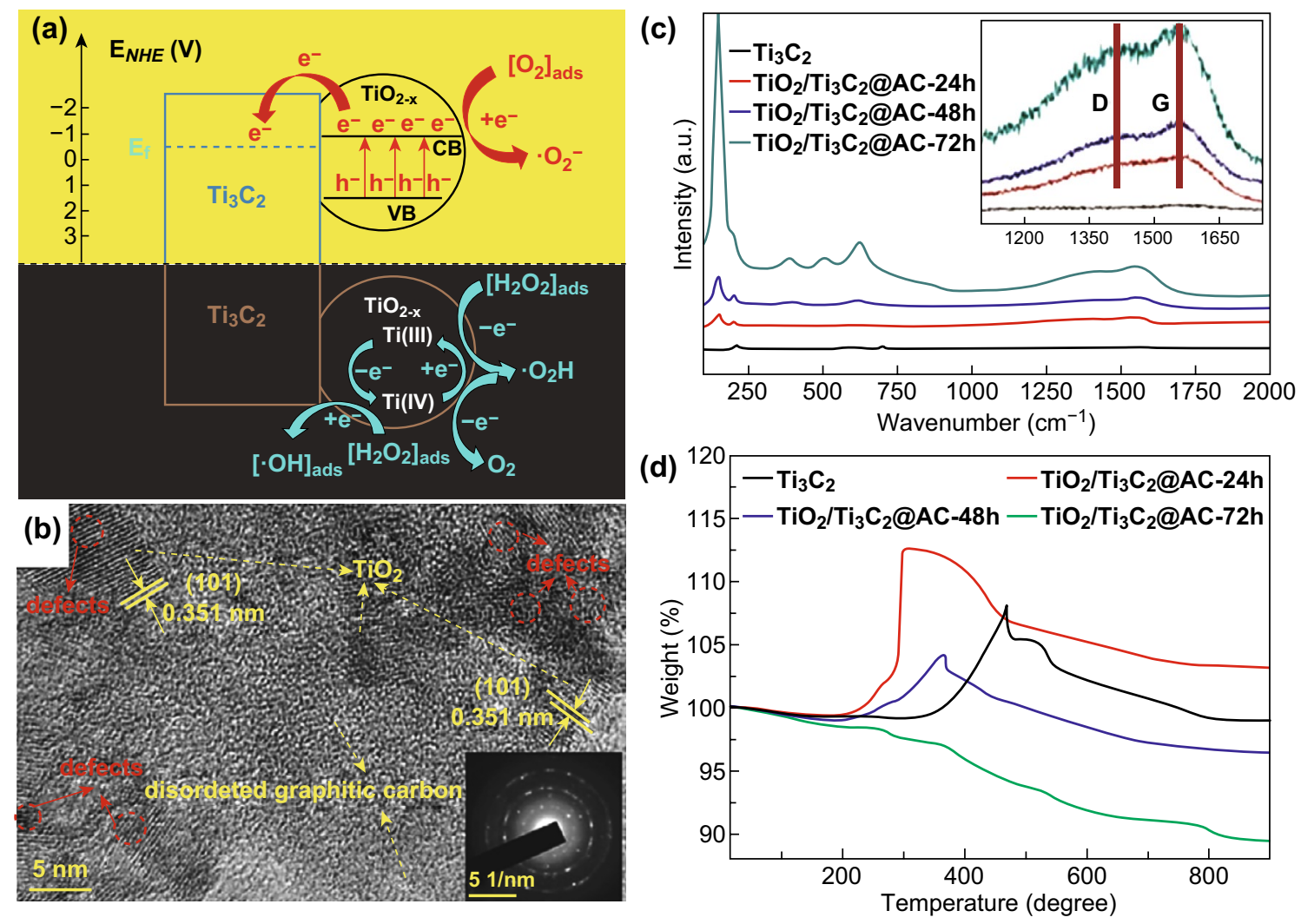

Fig. 9 MXene-derived photocatalysts synthesized by other in situ oxidation methods. a Mechanisms of degradation over mp-MXene/TiO ${ }_{2-x}$ from Cheng et al. Reprinted with permission from Ref. [100]. Copyright 2018 The Royal Society of Chemistry. b TEM image from Li et al. Reprinted with permission from Ref. [101]. Copyright 2018 Elsevier. c Raman spectra and d TGA from Sun et al. Reprinted with permission from Ref. [102]. Copyright 2018 The Royal Society of Chemistry

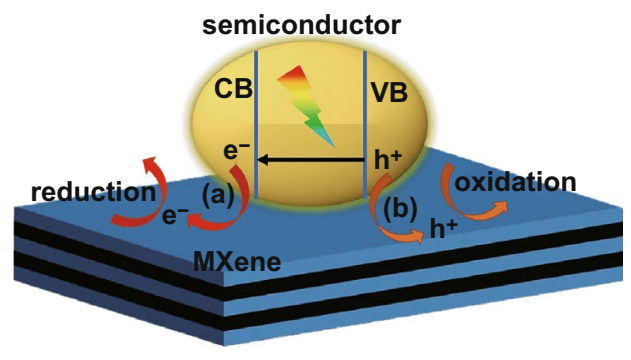

Fig. 10 Schematic of the working mechanism of MXenes applied in photocatalysis

from the photocatalyst to MXenes improves electron-hole pair separation and suppresses charge recombination in photocatalysts, thus enhancing the photoactivity.

Another advantage of using MXenes in photocatalysis is due to their termination groups. For example, $-\mathrm{O}$ termination groups show the best potential for hydrogen production because of their low $\mid \Delta G_{\mathrm{H}} \mathrm{I}$ and the availability of active sites for the adsorption of hydrogen atoms [70, 74].
Though termination groups are important in photocatalysis, currently, it has not been possible to precisely control the relative concentrations of the different termination groups. Using presently available synthetic methods, changing the different reaction conditions can partially modify the termination groups on MXenes surface and thereby affect their performance in photocatalysis.

\section{Conclusion and Outlook}

In summary, the application of MXenes in photocatalysis has shown rapid development since 2015. Among the MXenes family, $\mathrm{Ti}_{3} \mathrm{C}_{2}$ has been the most studied MXene. Mechanical mixing and self-assembly are mild and easy methods of synthesis, where the ratio of MXenes to the photocatalyst can be controlled. In addition, MXenes can also be doped into the photocatalysts by in situ decoration of a semiconductor photocatalyst. The large interfacial area afforded by 
the doping process improves electron transfer. However, the MXenes oxidation method has the advantage of obtaining both carbon and MXenes as co-catalysts by forming a metal oxide/MXenes/C structure. Though the above-mentioned four synthetic methods are generally used for photocatalysts, with further development in the field of MXenes, new processes may be discovered.

Besides developing improved synthetic methods, the other aspects that need to be focused on in the future are as follows:

1. Controlling the morphologies of MXenes. MXene flakes show larger surface area than multilayered MXenes, since mono- or few-layered MXenes provide a greater number of active sites for photocatalytic reactions. The flakes are also convenient for building structures, such as quantum dots, spheres, and nanorods. However, the instability of MXenes should be taken into account during heat treatment [107].

2. MXenes combine with efficient photocatalysts. MXenes can be used as co-catalysts to combine with many semiconductor photocatalysts due to their excellent electronic conductivity and the presence of numerous hydrophilic groups on the surface. Hundreds of semiconductor photocatalysts have been reported for photocatalysis so far. Attention should be paid to combining the efficient and cheap photocatalysts with MXenes to achieve better photocatalytic performance. So far, only g- $\mathrm{C}_{3} \mathrm{~N}_{4}, \mathrm{CdS}$, $\mathrm{ZnS}, \mathrm{TiO}_{2}, \mathrm{CuO}, \mathrm{Nb}_{2} \mathrm{O}_{5}, \mathrm{BiVO}_{4}, \mathrm{Ag}_{3} \mathrm{PO}_{4}, \alpha-\mathrm{Fe}_{2} \mathrm{O}_{3}$, $\mathrm{In}_{2} \mathrm{~S}_{3}, \mathrm{Bi}_{2} \mathrm{WO}_{6}, \mathrm{Bi}_{0.90} \mathrm{Gd}_{0.10} \mathrm{Fe}_{0.80} \mathrm{Sn}_{0.20} \mathrm{O}_{3}$, and $\mathrm{BiOBr}$ have been explored, with $\mathrm{TiO}_{2}$ and $\mathrm{g}-\mathrm{C}_{3} \mathrm{~N}_{4}$ attracting the most attention.

3. Surface modification of MXenes. Surface termination groups significantly affect the properties of MXenes, and thus, tuning the surface termination groups and modifying the MXenes surface are expected to greatly influence its potential as co-catalyst.

4. Synthesis of new MXenes. To date, only a small fraction of the different possible MXenes has been synthesized in laboratories. Some MXenes showing semiconducting properties have been reported based on theoretical calculations. Theoretical predictions help in the synthesis of semiconductor MXenes and applied in photocatalysis. Once obtained experimentally, potential MXenes can be applied as photocatalysts, thus widening the application range of MXenes. Moreover, new types of transition metal borides (MBenes) have also been predicted [34, 109] and have shown potential for photocatalysis applications. More work needs to be done in this direction.
5. Developing new synthesis methods for MXenes. HF and in situ HF wet chemical treatment are by far the most used methods in MXenes synthesis. Other HF-free methods are emerging and leading to MXenes with different properties. Yet, these have not been investigated in photocatalytic applications, and thus, the effect of the type of synthesis process used on the final performance of the MXene is currently not understood.

In short, due to tremendous effort of scientists worldwide, the great potential of MXenes in photocatalysis has been revealed. With the fast-growing development in this area, it is expected that more and more studies will focus on the applications of MXenes photocatalysis and pave the way to the commercialization of photocatalytic technologies based on these materials.

Acknowledgements This work was supported by the National Natural Science Foundation of China (No. 11574111 and No. 11974129 to X.-F. W.) and "the Fundamental Research Funds for the Central Universities."

Open Access This article is distributed under the terms of the Creative Commons Attribution 4.0 International License (http:// creativecommons.org/licenses/by/4.0/), which permits unrestricted use, distribution, and reproduction in any medium, provided you give appropriate credit to the original author(s) and the source, provide a link to the Creative Commons license, and indicate if changes were made.

\section{References}

1. M. Naguib, M. Kurtoglu, V. Presser, J. Lu, J. Niu et al., Twodimensional nanocrystals produced by exfoliation of $\mathrm{Ti}_{3} \mathrm{AlC}_{2}$. Adv. Mater. 23, 4248-4253 (2011). https://doi.org/10.1002/ adma.201102306

2. M. Naguib, V.N. Mochalin, M.W. Barsoum, Y. Gogotsi, 25th anniversary article: MXenes: a new family of two-dimensional materials. Adv. Mater. 26, 992-1005 (2014). https:// doi.org/10.1002/adma.201304138

3. B. Anasori, M.R. Lukatskaya, Y. Gogotsi, 2D metal carbides and nitrides (MXenes) for energy storage. Nat. Rev. Mater. 2, 16098 (2017). https://doi.org/10.1038/natrevmats.2016.98

4. M. Liu, Z. Yang, H. Sun, C. Lai, X. Zhao, H. Peng, T. Liu, A hybrid carbon aerogel with both aligned and interconnected pores as interlayer for high-performance lithium-sulfur batteries. Nano Res. 9, 3735-3746 (2016). https://doi. org/10.1007/s12274-016-1244-1

5. C. Hou, Z. Tai, L. Zhao, Y. Zhai, Y. Hou et al., High performance $\mathrm{MnO} @ \mathrm{C}$ microcages with a hierarchical structure and tunable carbon shell for efficient and durable lithium 
storage. J. Mater. Chem. A 6, 9723-9736 (2018). https://doi. org/10.1039/c8ta02863j

6. B. Kirubasankar, V. Murugadoss, J. Lin, T. Ding, M. Dong et al., In situ grown nickel selenide on graphene nanohybrid electrodes for high energy density asymmetric supercapacitors. Nanoscale 10, 20414-20425 (2018). https://doi. org/10.1039/c8nr06345a

7. M. Liu, Q. Meng, Z. Yang, X. Zhao, T. Liu, Ultra-long-term cycling stability of an integrated carbon-sulfur membrane with dual shuttle-inhibiting layers of graphene "nets" and a porous carbon skin. Chem. Commun. 54, 5090-5093 (2018). https://doi.org/10.1039/c8cc01889h

8. W. Du, X. Wang, J. Zhan, X. Sun, L. Kang et al., Biological cell template synthesis of nitrogen-doped porous hollow carbon spheres $/ \mathrm{MnO}_{2}$ composites for high-performance asymmetric supercapacitors. Electrochim. Acta 296, 907-915 (2019). https://doi.org/10.1016/j.electacta.2018.11.074

9. C. Hou, J. Wang, W. Du, J. Wang, Y. Du et al., One-pot synthesized molybdenum dioxide-molybdenum carbide heterostructures coupled with 3D holey carbon nanosheets for highly efficient and ultrastable cycling lithium-ion storage. J. Mater. Chem. A 7, 13460-13472 (2019). https://doi. org/10.1039/c9ta03551f

10. M. Idrees, S. Batool, J. Kong, Q. Zhuang, H. Liu et al., Polyborosilazane derived ceramics-nitrogen sulfur dual doped graphene nanocomposite anode for enhanced lithium ion batteries. Electrochim. Acta 296, 925-937 (2019). https:// doi.org/10.1016/j.electacta.2018.11.088

11. K. Le, Z. Wang, F. Wang, Q. Wang, Q. Shao et al., Sandwichlike NiCo layered double hydroxide/reduced graphene oxide nanocomposite cathodes for high energy density asymmetric supercapacitors. Dalton Trans. 48, 5193-5202 (2019). https ://doi.org/10.1039/c9dt00615j

12. R. Li, X. Zhu, Q. Fu, G. Liang, Y. Chen et al., Nanosheetbased $\mathrm{Nb}_{12} \mathrm{O}_{29}$ hierarchical microspheres for enhanced lithium storage. Chem. Commun. 55, 2493-2496 (2019). https ://doi.org/10.1039/c8cc09924c

13. Y. Ma, C. Hou, H. Zhang, Q. Zhang, H. Liu, S. Wu, Z. Guo, Three-dimensional core-shell $\mathrm{Fe}_{3} \mathrm{O}_{4}$ /polyaniline coaxial heterogeneous nanonets: Preparation and high performance supercapacitor electrodes. Electrochim. Acta 315, 114-123 (2019). https://doi.org/10.1016/j.electacta.2019.05.073

14. L. Yang, M. Shi, J. Jiang, Y. Liu, C. Yan, H. Liu, Z. Guo, Heterogeneous interface induced formation of balsam pearlike ppy for high performance supercapacitors. Electrochim. Acta 244, 27-30 (2019). https://doi.org/10.1016/j.matle t.2019.02.064

15. M. Liu, Y. Liu, Y. Yan, F. Wang, J. Liu, T. Liu, A highly conductive carbon-sulfur film with interconnected mesopores as an advanced cathode for lithium-sulfur batteries. Chem. Commun. 53, 9097-9100 (2017). https://doi.org/10.1039/ c7cc04523a

16. T. Hisatomi, K. Domen, Introductory lecture: sunlight-driven water splitting and carbon dioxide reduction by heterogeneous semiconductor systems as key processes in artificial photosynthesis. Faraday Discuss. 198, 11-35 (2017). https ://doi.org/10.1039/c6fd00221h

17. V.-H. Nguyen, J.C.S. Wu, Recent developments in the design of photoreactors for solar energy conversion from water splitting and $\mathrm{CO}_{2}$ reduction. Appl. Cataly. A Gen. 550, 122-141 (2018). https://doi.org/10.1016/j.apcata.2017.11.002

18. X. Zhang, Z. Zhang, J. Li, X. Zhao, D. Wu, Z. Zhou, $\mathrm{Ti}_{2} \mathrm{CO}_{2}$ MXene: a highly active and selective photocatalyst for $\mathrm{CO}_{2}$ reduction. J. Mater. Chem. A 5, 12899-12903 (2017). https ://doi.org/10.1039/c7ta03557h

19. Q. Liu, L. Ai, J. Jiang, MXene-derived $\mathrm{TiO}_{2} @ \mathrm{C} / \mathrm{g}-\mathrm{C}_{3} \mathrm{~N}_{4}$ heterojunctions for highly efficient nitrogen photofixation. J. Mater. Chem. A 6, 4102-4110 (2018). https://doi. org/10.1039/c7ta09350k

20. J. Low, J. Yu, M. Jaroniec, S. Wageh, A.A. Al-Ghamdi, Heterojunction photocatalysts. Adv. Mater. 29, 1601694 1601713 (2017). https://doi.org/10.1002/adma.201601694

21. D. Pan, S. Ge, J. Zhao, Q. Shao, L. Guo, X. Zhang, J. Lin, G. $\mathrm{Xu}, \mathrm{Z}$. Guo, Synthesis, characterization and photocatalytic activity of mixed-metal oxides derived from NiCoFe ternary layered double hydroxides. Dalton Trans. 47, 9765-9778 (2018). https://doi.org/10.1039/c8dt01045e

22. J. Zhao, S. Ge, D. Pan, Q. Shao, J. Lin et al., Solvothermal synthesis, characterization and photocatalytic property of zirconium dioxide doped titanium dioxide spinous hollow microspheres with sunflower pollen as bio-templates. J. Colloid Interface Sci. 529, 111-121 (2018). https://doi. org/10.1016/j.jcis.2018.05.091

23. Y. Sheng, J. Yang, F. Wang, L. Liu, H. Liu, C. Yan, Z. Guo, Sol-gel synthesized hexagonal boron nitride/titania nanocomposites with enhanced photocatalytic activity. Appl. Surf. Sci. 465, 154-163 (2019). https://doi.org/10.1016/j.apsus c. 2018.09 .137

24. J. Tian, Q. Shao, J. Zhao, D. Pan, M. Dong et al., Microwave solvothermal carboxymethyl chitosan templated synthesis of $\mathrm{TiO}_{2} / \mathrm{ZrO}_{2}$ composites toward enhanced photocatalytic degradation of Rhodamine B. J. Colloid Interface Sci. 541, 18-29 (2019). https://doi.org/10.1016/j.jcis.2019.01.069

25. J. Zhao, S. Ge, D. Pan, Y. Pan, V. Murugadoss et al., Microwave hydrothermal synthesis of $\mathrm{In}_{2} \mathrm{O}_{3}-\mathrm{ZnO}$ nanocomposites and their enhanced photoelectrochemical properties. J. Electrochem. Soc. 166, H3074-H3083 (2019). https://doi. org/10.1149/2.0071905jes

26. H. Shindume, L.Z. Zhao, N. Wang, H. Liu, A. Umar, J. Zhang, T. Wu, Z. Guo, Enhanced photocatalytic activity of $\mathrm{B}, \mathrm{N}$-codoped $\mathrm{TiO}_{2}$ by a new molten nitrate process. Electrochim. Acta 19, 839-849 (2019). https://doi.org/10.1166/ jnn.2019.15745

27. Z. Zhao, H. An, J. Lin, M. Feng, V. Murugadoss et al., Progress on the photocatalytic reduction removal of chromium contamination. Chem. Rec. 19, 873-882 (2019). https://doi. org/10.1002/tcr.201800153

28. G. Zheng, J. Wang, H. Liu, V. Murugadoss, G. Zu et al., Tungsten oxide nanostructures and nanocomposites for photoelectrochemical water splitting. Nanoscale (advance Article, 2019). https://doi.org/10.1039/c9nr03474a 
29. B. Lin, Z. Lin, S. Chen, M. Yu, W. Li et al., Surface intercalated spherical $\mathrm{MoS}_{2 \mathrm{x}} \mathrm{Se}_{2(1-\mathrm{x})}$ nanocatalysts for highly efficient and durable hydrogen evolution reactions. Dalton Trans. 48, 8279-8287 (2019). https://doi.org/10.1039/c9dt01218d

30. T. Su, Q. Shao, Z. Qin, Z. Guo, Z. Wu, Role of interfaces in two-dimensional photocatalyst for water splitting. ACS Catal. 8, 2253-2276 (2018). https://doi.org/10.1021/acscatal.7b034 37

31. M. Ge, J. Cai, J. Iocozzia, C. Cao, J. Huang et al., A review of $\mathrm{TiO}_{2}$ nanostructured catalysts for sustainable $\mathrm{H}_{2}$ generation. Int. J. Hydrog. Energy 42, 8418-8449 (2017). https:// doi.org/10.1016/j.ijhydene.2016.12.052

32. L. Clarizia, D. Russo, I. Di Somma, R. Andreozzi, R. Marotta, Hydrogen generation through solar photocatalytic processes: a review of the configuration and the properties of effective metal-based semiconductor nanomaterials. Energies 10, 1624-1644 (2017). https://doi.org/10.3390/en10101624

33. X. Zhang, Z. Zhang, Z. Zhou, MXene-based materials for electrochemical energy storage. J. Energy Chem. 27, 73-85 (2018). https://doi.org/10.1016/j.jechem.2017.08.004

34. Z. Guo, J. Zhou, Z. Sun, New two-dimensional transition metal borides for $\mathrm{Li}$ ion batteries and electrocatalysis. J. Mater. Chem. A 5, 23530-23535 (2017). https://doi. org/10.1039/c7ta08665b

35. H. Jiang, Z. Wang, Q. Yang, L. Tan, L. Dong, M. Dong, Ultrathin $\mathrm{Ti}_{3} \mathrm{C}_{2} \mathrm{~T}$ (MXene) nanosheet-wrapped $\mathrm{NiSe}_{2}$ octahedral crystal for enhanced supercapacitor performance and synergetic electrocatalytic water splitting. Nano-Micro Lett. 11, 31 (2019). https://doi.org/10.1007/s40820-019-0261-5

36. Y.T. Liu, P. Zhang, N. Sun, B. Anasori, Q.Z. Zhu, H. Liu, Y. Gogotsi, B. Xu, Self-assembly of transition metal oxide nanostructures on MXene nanosheets for fast and stable lithium storage. Adv. Mater. 30, 1707334 (2018). https://doi. org/10.1002/adma.201707334

37. L. Yu, L. Hu, B. Anasori, Y.-T. Liu, Q. Zhu, P. Zhang, Y. Gogotsi, B. Xu, MXene-bonded activated carbon as a flexible electrode for high-performance supercapacitors. ACS Energy Lett. 3, 1597-1603 (2018). https://doi.org/10.1021/acsenergyl ett. 8 b00718

38. H. Liu, X. Zhang, Y. Zhu, B. Cao, Q. Zhu et al., Electrostatic self-assembly of OD-2D $\mathrm{SnO}_{2}$ quantum dots/ $\mathrm{Ti}_{3} \mathrm{C}_{2} \mathrm{~T}_{x}$ MXene hybrids as anode for lithium-ion batteries. Nano-Micro Lett. 11, 65 (2019). https://doi.org/10.1007/s40820-019-0296-7

39. F. Shahzad, M. Alhabeb, C.B. Hatter, B. Anasori, H.S. Man, C.M. Koo, Y. Gogotsi, Electromagnetic interference shielding with 2D transition metal carbides (MXenes). Science 353, 1137 (2016). https://doi.org/10.1126/science.aag2421

40. M. Han, X. Yin, X. Li, B. Anasori, L. Zhang, L. Cheng, Y. Gogotsi, Laminated and two-dimensional carbon-supported microwave absorbers derived from MXenes. ACS Appl. Mater. Interfaces 9, 20038-20045 (2017). https://doi. org/10.1021/acsami.7b04602

41. J. Zhu, E. Ha, G. Zhao, Y. Zhou, D. Huang et al., Recent advance in MXenes: a promising 2D material for catalysis, sensor and chemical adsorption. Coord. Chem. Rev. 352, 306-327 (2017). https://doi.org/10.1016/j.ccr.2017.09.012
42. A. Sarycheva, A. Polemi, Y. Liu, K. Dandekar, B. Anasori, Y. Gogotsi, 2D titanium carbide (MXene) for wireless communication. Sci. Adv. 4, eaau0920 (2018). https://doi. org/10.1126/sciadv.aau0920

43. Y. Ying, Y. Liu, X. Wang, Y. Mao, W. Cao, P. Hu, X. Peng, Two-dimensional titanium carbide for efficiently reductive removal of highly toxic chromium(VI) from water. ACS Appl. Mater. Interfaces 7, 1795-1803 (2015). https://doi. org/10.1021/am5074722

44. N. Liu, N. Lu, Y. Su, P. Wang, X. Quan, Fabrication of g- $\mathrm{C}_{3} \mathrm{~N}_{4} / \mathrm{Ti}_{3} \mathrm{C}_{2}$ composite and its visible-light photocatalytic capability for ciprofloxacin degradation. Sep. Purif. Technol. 211, 782-789 (2019). https://doi.org/10.1016/j.seppu r.2018.10.027

45. C. Dall'Agnese, Y. Dall'Agnese, B. Anasori, W. Sugimoto, S. Mori, Oxidized $\mathrm{Ti}_{3} \mathrm{C}_{2}$ MXene nanosheets for dye-sensitized solar cells. New J. Chem. 42, 16446-16450 (2018). https:// doi.org/10.1039/c8nj03246g

46. L. Yang, Y. Dall'Agnese, K. Hantanasirisakul, C.E. Shuck, K. Maleski et al., $\mathrm{SnO}_{2}-\mathrm{Ti}_{3} \mathrm{C}_{2}$ MXene electron transport layers for perovskite solar cells. J. Mater. Chem. A 7, 5635-5642 (2019). https://doi.org/10.1039/c8ta12140k

47. H.C. Fu, V. Ramalingam, H. Kim, C.H. Lin, X. Fang, H.N. Alshareef, J.H. He, MXene-contacted silicon solar cells with $11.5 \%$ efficiency. Adv. Energy Mater. (2019). https://doi. org/10.1002/aenm.201900180

48. H. Wang, Y. Wu, X. Yuan, G. Zeng, J. Zhou, X. Wang, J.W. Chew, Clay-inspired MXene-based electrochemical devices and photo-electrocatalyst: state-of-the-art progresses and challenges. Adv. Mater. 30, 1704561 (2018). https://doi. org/10.1002/adma.201704561

49. M. Li, J. Lu, K. Luo, Y. Li, K. Chang et al., Element replacement approach by reaction with lewis acidic molten salts to synthesize nanolaminated MAX phases and MXenes. J. Am. Chem. Soc. 141, 4730-4737 (2019). https://doi.org/10.1021/ jacs.9b00574

50. X. Lu, K. Xu, P. Chen, K. Jia, S. Liu, C. Wu, Facile one step method realizing scalable production of $\mathrm{g}-\mathrm{c}_{3} \mathrm{n}_{4}$ nanosheets and study of their photocatalytic $\mathrm{H}_{2}$ evolution activity. J. Mater. Chem. A 2, 18924-18928 (2014). https://doi. org/10.1039/c4ta04487h

51. J. Peng, X. Chen, W.-J. Ong, X. Zhao, N. Li, Surface and heterointerface engineering of 2D MXenes and their nanocomposites: insights into electro- and photocatalysis. Chem 5, 18-50 (2019). https://doi.org/10.1016/j.chempr.2018.08.037

52. Z.W. Seh, K.D. Fredrickson, B. Anasori, J. Kibsgaard, A.L. Strickler et al., Two-dimensional molybdenum carbide (MXene) as an efficient electrocatalyst for hydrogen evolution. ACS Energy Lett. 1, 589-594 (2016). https://doi. org/10.1021/acsenergylett.6b00247

53. M. Alhabeb, K. Maleski, T.S. Mathis, A. Sarycheva, C.B. Hatter, S. Uzun, A. Levitt, Y. Gogotsi, Selective etching of silicon from $\mathrm{Ti}_{3} \mathrm{SiC}_{2}$ (MAX) to obtain 2D titanium carbide (MXene). Angew. Chem. Int. Ed. 57, 5444-5448 (2018). https://doi.org/10.1002/anie.201802232 
54. J. Xuan, Z. Wang, Y. Chen, D. Liang, L. Cheng et al., Organic-base-driven intercalation and delamination for the production of functionalized titanium carbide nanosheets with superior photothermal therapeutic performance. Angew. Chem. Int. Ed. 128, 14789-14794 (2016). https:// doi.org/10.1002/ange.201606643

55. S. Yang, P. Zhang, F. Wang, A.G. Ricciardulli, M.R. Lohe, P.W.M. Blom, X. Feng, Fluoride-free synthesis of twodimensional titanium carbide (MXene) using a binary aqueous system. Angew. Chem. Int. Ed. 57, 15491-15495 (2018). https://doi.org/10.1002/anie.201809662

56. M.R. Lukatskaya, J. Halim, B. Dyatkin, M. Naguib, Y.S. Buranova et al., Room-temperature carbide-derived carbon synthesis by electrochemical etching of MAX phases. Angew. Chem. Int. Ed. 53, 4877-4880 (2014). https://doi. org/10.1002/anie.201402513

57. S.Y. Pang, Y.T. Wong, S. Yuan, Y. Liu, M.K. Tsang et al., Universal strategy for HF-free facile and rapid synthesis of two-dimensional MXenes as multifunctional energy materials. J. Am. Chem. Soc. 141(24), 9610-9616 (2019). https:// doi.org/10.1021/jacs.9b02578

58. T. Li, L. Yao, Q. Liu, J. Gu, R. Luo et al., Fluorine-free synthesis of high-purity $\mathrm{Ti}_{3} \mathrm{C}_{2} \mathrm{~T}_{x}(\mathrm{~T}=\mathrm{OH}, \mathrm{O})$ via alkali treatment. Angew. Chem. Int. Ed. 57, 6115-6119 (2018). https:// doi.org/10.1002/anie.201800887

59. M. Alhabeb, K. Maleski, B. Anasori, P. Lelyukh, L. Clark, S. Sin, Y. Gogotsi, Guidelines for synthesis and processing of two-dimensional titanium carbide $\left(\mathrm{Ti}_{3} \mathrm{C}_{2} \mathrm{~T}_{x}\right.$ MXene). Chem. Mater. 29, 7633-7644 (2017). https://doi.org/10.1021/acs. chemmater.7b02847

60. X. Xiao, H. Wang, P. Urbankowski, Y. Gogotsi, Topochemical synthesis of 2D materials. Chem. Soc. Rev. 47, 87448765 (2018). https://doi.org/10.1039/c8cs00649k

61. V.M. Ng, H. Huang, K. Zhou, P.S. Lee, W. Que, J.Z. Xu, L.B. Kong, Recent progress in layered transition metal carbides and/or nitrides (MXenes) and their composites: synthesis and applications. J. Mater. Chem. A 5(7), 3039-3068 (2017). https://doi.org/10.1039/c6ta06772g

62. J. Pang, R.G. Mendes, A. Bachmatiuk, L. Zhao, H.Q. Ta et al., Applications of 2D MXenes in energy conversion and storage systems. Chem. Soc. Rev. 48, 72-133 (2019). https ://doi.org/10.1039/c8cs00324f

63. Z. Guo, J. Zhou, L. Zhu, Z. Sun, MXene: a promising photocatalyst for water splitting. J. Mater. Chem. A 4, 1144611452 (2016). https://doi.org/10.1039/c6ta04414j

64. S.-Y. Xie, J.-H. Su, H. Zheng, Group-IV analogues of MXene: promising two-dimensional semiconductors. Solid State Commun. 291, 51-53 (2019). https://doi.org/10.1016/j. ssc.2019.01.017

65. C.-F. Fu, X. Li, Q. Luo, J. Yang, Two-dimensional multilayer $\mathrm{M}_{2} \mathrm{CO}_{2}(\mathrm{M}=\mathrm{Sc}, \mathrm{Zr}, \mathrm{Hf})$ as photocatalysts for hydrogen production from water splitting: a first principles study. J. Mater. Chem. A 5, 24972-24980 (2017). https://doi.org/10.1039/ c7ta08812d

66. Z. Guo, N. Miao, J. Zhou, B. Sa, Z. Sun, Strain-mediated type-I/type-II transition in MXene/blue phosphorene van der Waals heterostructures for flexible optical/electronic devices. J. Mater. Chem. C 5, 978-984 (2017). https://doi. org/10.1039/c6tc04349f

67. J. Cui, Q. Peng, J. Zhou, Z. Sun, Strain-tunable electronic structures and optical properties of semiconducting MXenes. Nanotechnology 30, 345205 (2019). https://doi. org/10.1088/1361-6528/ab1f22

68. A. Mostafaei, E. Faizabadi, E.H. Semiromi, Theoretical studies and tuning the electronic and optical properties of $\mathrm{Zr}_{2} \mathrm{CO}_{2}$ monolayer using biaxial strain effect: modified Becke-Johnson calculation. Physica E 114, 113559 (2019). https://doi. org/10.1016/j.physe.2019.113559

69. M. Ye, X. Wang, E. Liu, J. Ye, D. Wang, Boosting the photocatalytic activity of P25 for carbon dioxide reduction by using a surface-alkalinized titanium carbide MXene as cocatalyst. Chemsuschem 11, 1606-1611 (2018). https://doi. org/10.1002/cssc. 201800083

70. J. Ran, G. Gao, F.T. Li, T.Y. Ma, A. Du, S.Z. Qiao, $\mathrm{Ti}_{3} \mathrm{C}_{2}$ MXene co-catalyst on metal sulfide photo-absorbers for enhanced visible-light photocatalytic hydrogen production. Nat. Commun. 8, 13907 (2017). https://doi.org/10.1038/ ncomms 13907

71. C. Peng, X. Yang, Y. Li, H. Yu, H. Wang, F. Peng, Hybrids of two-dimensional $\mathrm{Ti}_{3} \mathrm{C}_{2}$ and $\mathrm{TiO}_{2}$ exposing 001 facets toward enhanced photocatalytic activity. ACS Appl. Mater. Interfaces 8, 6051-6060 (2016). https://doi.org/10.1021/acsam i.5b11973

72. X. An, W. Wang, J. Wang, H. Duan, J. Shi, X. Yu, The synergetic effects of $\mathrm{Ti}_{3} \mathrm{C}_{2}$ MXene and Pt as co-catalysts for highly efficient photocatalytic hydrogen evolution over $\mathrm{g}-\mathrm{C}_{3} \mathrm{~N}_{4}$. Phys. Chem. Chem. Phys. 20, 11405-11411 (2018). https:// doi.org/10.1039/c8cp01123k

73. X. Xie, N. Zhang, Z.-R. Tang, M. Anpo, Y.-J. Xu, $\mathrm{Ti}_{3} \mathrm{C}_{2} \mathrm{~T}_{x}$ MXene as a Janus cocatalyst for concurrent promoted photoactivity and inhibited photocorrosion. Appl. Catal. B 237, 43-49 (2018). https://doi.org/10.1016/j.apcatb.2018.05.070

74. Y. Sun, D. Jin, Y. Sun, X. Meng, Y. Gao et al., G- $\mathrm{C}_{3} \mathrm{~N}_{4} /$ $\mathrm{Ti}_{3} \mathrm{C}_{2} \mathrm{~T}_{x}$ (MXenes) composite with oxidized surface groups for efficient photocatalytic hydrogen evolution. J. Mater. Chem. A 6, 9124-9131 (2018). https://doi.org/10.1039/c8ta0 2706d

75. T. Cai, L. Wang, Y. Liu, S. Zhang, W. Dong et al., $\mathrm{Ag}_{3} \mathrm{PO}_{4} /$ $\mathrm{Ti}_{3} \mathrm{C}_{2}$ MXene interface materials as a Schottky catalyst with enhanced photocatalytic activities and anti-photocorrosion performance. Appl. Catal. B 239, 545-554 (2018). https:// doi.org/10.1016/j.apcatb.2018.08.053

76. H. Zhang, M. Li, J. Cao, Q. Tang, P. Kang, C. Zhu, M. Ma, $2 \mathrm{D}$ a- $\mathrm{Fe}_{2} \mathrm{O}_{3}$ doped $\mathrm{Ti}_{3} \mathrm{C}_{2}$ MXene composite with enhanced visible light photocatalytic activity for degradation of Rhodamine B. Ceram. Int. 44, 19958-19962 (2018). https://doi. org/10.1016/j.ceramint.2018.07.262

77. T. Su, Z.D. Hood, M. Naguib, L. Bai, S. Luo et al., Monolayer $\mathrm{Ti}_{3} \mathrm{C}_{2} \mathrm{~T}_{x}$ as an effective co-catalyst for enhanced photocatalytic hydrogen production over $\mathrm{TiO}_{2}$. ACS Appl. Energy Mater. 2, 4640-4651 (2019). https://doi.org/10.1021/acsae $\mathrm{m} .8 \mathrm{~b} 02268$ 
78. T. Su, Z.D. Hood, M. Naguib, L. Bai, S. Luo et al., 2D/2D heterojunction of $\mathrm{Ti}_{3} \mathrm{C}_{2} / g-\mathrm{C}_{3} \mathrm{~N}_{4}$ nanosheets for enhanced photocatalytic hydrogen evolution. Nanoscale 11, 8138-8149 (2019). https://doi.org/10.1039/c9nr00168a

79. J.-H. Zhao, L.-W. Liu, K. Li, T. Li, F.-T. Liu, Conductive $\mathrm{Ti}_{3} \mathrm{C}_{2}$ and MOF-derived $\mathrm{CoS}_{\mathrm{x}}$ boosting the photocatalytic hydrogen production activity of $\mathrm{TiO}_{2}$. CrystEngComm 21, 2416-2421 (2019). https://doi.org/10.1039/c8ce02050g

80. R. Chen, P. Wang, J. Chen, C. Wang, Y. Ao, Synergetic effect of $\mathrm{MoS}_{2}$ and MXene on the enhanced $\mathrm{H}_{2}$ evolution performance of CdS under visible light irradiation. Appl. Surf. Sci. 473, 11-19 (2019). https://doi.org/10.1016/j.apsus c.2018.12.071

81. M. Shao, Y. Shao, J. Chai, Y. Qu, M. Yang et al., Synergistic effect of $2 \mathrm{D} \mathrm{Ti}{ }_{2} \mathrm{C}$ and $\mathrm{g}-\mathrm{C}_{3} \mathrm{~N}_{4}$ for efficient photocatalytic hydrogen production. J. Mater. Chem. A 5, 16748-16756 (2017). https://doi.org/10.1039/c7ta04122e

82. Y. Xu, S. Wang, J. Yang, B. Han, R. Nie et al., Highly efficient photoelectrocatalytic reduction of $\mathrm{CO}_{2}$ on the $\mathrm{Ti}_{3} \mathrm{C}_{2} / \mathrm{g}-\mathrm{C}_{3} \mathrm{~N}_{4}$ heterojunction with rich $\mathrm{Ti}^{3+}$ and pyri-N species. J. Mater. Chem. A 6, 15213-15220 (2018). https://doi.org/10.1039/ c8ta03315c

83. Y. Gao, L. Wang, A. Zhou, Z. Li, J. Chen, H. Bala, Q. Hu, $\mathrm{X}$. Cao, Hydrothermal synthesis of $\mathrm{TiO}_{2} / \mathrm{Ti}_{3} \mathrm{C}_{2}$ nanocomposites with enhanced photocatalytic activity. Mater. Lett. 150, 62-64 (2015). https://doi.org/10.1016/j.matlet.2015.02.135

84. H. Wang, R. Peng, Z.D. Hood, M. Naguib, S.P. Adhikari, Z. $\mathrm{Wu}$, Titania composites with $2 \mathrm{D}$ transition metal carbides as photocatalysts for hydrogen production under visible-light irradiation. Chemsuschem 9, 1490-1497 (2016). https://doi. org/10.1002/cssc. 201600165

85. L. Shi, C. Xu, D. Jiang, X. Sun, X. Wang et al., Enhanced interaction in $\mathrm{TiO}_{2} / \mathrm{BiVO}_{4}$ heterostructures via MXene $\mathrm{Ti}_{3} \mathrm{C}_{2}$-derived 2D-carbon for highly efficient visible-light photocatalysis. Nanotechnology 30, 075601 (2019). https:// doi.org/10.1088/1361-6528/aaf313

86. Q. Luo, B. Chai, M. Xu, Q. Cai, Preparation and photocatalytic activity of $\mathrm{TiO}_{2}$-loaded $\mathrm{Ti}_{3} \mathrm{C}_{2}$ with small interlayer spacing. Appl. Phys. A 124, 495 (2018). https://doi.org/10.1007/ s00339-018-1909-6

87. C. Liu, Q. Xu, Q. Zhang, Y. Zhu, M. Ji et al., Layered BiOBr/ $\mathrm{Ti}_{3} \mathrm{C}_{2}$ MXene composite with improved visible-light photocatalytic activity. J. Mater. Sci. 54, 2458-2471 (2018). https ://doi.org/10.1007/s10853-018-2990-0

88. S. Cao, B. Shen, T. Tong, J. Fu, J. Yu, 2D/2D heterojunction of ultrathin $\mathrm{MXene} / \mathrm{Bi}_{2} \mathrm{WO}_{6}$ nanosheets for improved photocatalytic $\mathrm{CO}_{2}$ reduction. Adv. Funct. Mater. 28, 1800136 (2018). https://doi.org/10.1002/adfm.201800136

89. A. Tariq, S.I. Ali, D. Akinwande, S. Rizwan, Efficient visiblelight photocatalysis of 2D-MXene nanohybrids with $\mathrm{Gd}^{3+}$ and $\mathrm{Sn}^{4+}$-codoped bismuth ferrite. ACS Omega 3, 1382813836 (2018). https://doi.org/10.1021/acsomega.8b01951

90. H. Wang, Y. Wu, T. Xiao, X. Yuan, G. Zeng et al., Formation of quasi-core-shell $\mathrm{In}_{2} \mathrm{~S}_{3}$ /anatase $\mathrm{TiO}_{2} @$ metallic $\mathrm{Ti}_{3} \mathrm{C}_{2} \mathrm{~T}_{x}$ hybrids with favorable charge transfer channels for excellent visible-light-photocatalytic performance. Appl. Catalysis
B 233, 213-225 (2018). https://doi.org/10.1016/j.apcat b. 2018.04 .012

91. L. Tie, S. Yang, C. Yu, H. Chen, Y. Liu, S. Dong, J. Sun, J. Sun, In situ decoration of $\mathrm{ZnS}$ nanoparticles with $\mathrm{Ti}_{3} \mathrm{C}_{2}$ MXene nanosheets for efficient photocatalytic hydrogen evolution. J. Colloid Interface Sci. 545, 63-70 (2019). https://doi. org/10.1016/j.jcis.2019.03.014

92. T. Wojciechowski, A. Rozmyslowska-Wojciechowska, G. Matyszczak, M. Wrzecionek, A. Olszyna et al., $\mathrm{Ti}_{2} \mathrm{C}$ MXene modified with ceramic oxide and noble metal nanoparticles: synthesis, morphostructural properties, and high photocatalytic activity. Inorg. Chem. 58, 7602-7614 (2019). https://doi. org/10.1021/acs.inorgchem.9b01015

93. C. Peng, H. Wang, H. Yu, F. Peng, (111) $\mathrm{TiO}_{2-x} / \mathrm{Ti}_{3} \mathrm{C}_{2}$ : Synergy of active facets, interfacial charge transfer and $\mathrm{Ti}^{3+}$ doping for enhance photocatalytic activity. Mater. Res. Bull. 89, 16-25 (2017). https://doi.org/10.1016/j.materresbu 11.2016.12.049

94. G. Jia, Y. Wang, X. Cui, W. Zheng, Highly carbon-doped $\mathrm{TiO}_{2}$ derived from MXene boosting the photocatalytic hydrogen evolution. ACS Sustain. Chem. Eng. 6, 13480-13486 (2018). https://doi.org/10.1021/acssuschemeng.8b03406

95. C. Peng, P. Wei, X. Li, Y. Liu, Y. Cao et al., High efficiency photocatalytic hydrogen production over ternary $\mathrm{Cu} / \mathrm{TiO}_{2} @$ $\mathrm{Ti}_{3} \mathrm{C}_{2} \mathrm{~T}_{x}$ enabled by low-work-function $2 \mathrm{D}$ titanium carbide. Nano Energy 53, 97-107 (2018). https://doi.org/10.1016/j. nanoen.2018.08.040

96. Y. Lu, M. Yao, A. Zhou, Q. Hu, L. Wang, Preparation and photocatalytic performance of $\mathrm{Ti}_{3} \mathrm{C}_{2} / \mathrm{TiO}_{2} / \mathrm{CuO}$ ternary nanocomposites. J. Nanomater. 2017, 1978764 (2017). https://doi. org/10.1155/2017/1978764

97. W. Yuan, L. Cheng, Y. Zhang, H. Wu, L. Zheng, 2D layered Carbon/ $\mathrm{TiO}_{2}$ hybrids derived from $\mathrm{Ti}_{3} \mathrm{C}_{2}$ MXenes for photocatalytic hydrogen evolution under visible light irradiation. Adv. Mater. Interfaces 4, 1700577 (2017). https://doi. org/10.1002/admi.201700577

98. J. Low, L. Zhang, T. Tong, B. Shen, J. Yu, $\mathrm{TiO}_{2} / \mathrm{MXene} \mathrm{Ti}_{3} \mathrm{C}_{2}$ composite with excellent photocatalytic $\mathrm{CO}_{2}$ reduction activity. J. Catal. 361, 255-266 (2018). https://doi.org/10.1016/j. jcat.2018.03.009

99. T. Su, R. Peng, Z.D. Hood, M. Naguib, I.N. Ivanov et al., One-step synthesis of $\mathrm{Nb}_{2} \mathrm{O}_{5} / \mathrm{C} / \mathrm{Nb}_{2} \mathrm{C}$ (MXene) composites and their use as photocatalysts for hydrogen evolution. Chemsuschem 11, 688-699 (2018). https://doi.org/10.1002/ cssc. 201702317

100. X. Cheng, L. Zu, Y. Jiang, D. Shi, X. Cai, Y. Ni, S. Lin, Y. Qin, A titanium-based photo-fenton bifunctional catalyst of $\mathrm{mp}-\mathrm{MXene} / \mathrm{TiO}_{2-x}$ nanodots for dramatic enhancement of catalytic efficiency in advanced oxidation processes. Chem. Commun. 54, 11622-11625 (2018). https://doi.org/10.1039/ c8cc05866k

101. J. Li, S. Wang, Y. Du, W. Liao, Enhanced photocatalytic performance of $\mathrm{TiO}_{2} @ \mathrm{C}$ nanosheets derived from two-dimensional $\mathrm{Ti}_{2} \mathrm{CT}_{x}$. Ceram. Int. 44, 7042-7046 (2018). https://doi. org/10.1016/j.ceramint.2018.01.139 
102. Y. Sun, Y. Sun, X. Meng, Y. Gao, Y. Dall'Agnese et al., Eosin Y-sensitized partially oxidized $\mathrm{Ti}_{3} \mathrm{C}_{2}$ MXene for photocatalytic hydrogen evolution. Catal. Sci. Technol. 9, 310-315 (2019). https://doi.org/10.1039/c8cy02240b

103. Y. Li, X. Deng, J. Tian, Z. Liang, H. Cui, $\mathrm{Ti}_{3} \mathrm{C}_{2}$ MXenederived $\mathrm{Ti}_{3} \mathrm{C}_{2} / \mathrm{TiO}_{2}$ nanoflowers for noble-metal-free photocatalytic overall water splitting. Appl. Mater. Today 13, 217-227 (2018). https://doi.org/10.1016/j.apmt.2018.09.004

104. W. Yuan, L. Cheng, Y. An, S. Lv, H. Wu, X. Fan, Y. Zhang, X. Guo, J. Tang, Laminated hybrid junction of sulfur-doped $\mathrm{TiO}_{2}$ and a carbon substrate derived from $\mathrm{Ti}_{3} \mathrm{C}_{2}$ MXenes: toward highly visible light-driven photocatalytic hydrogen evolution. Adv. Sci. 5, 1700870 (2018). https://doi. org/10.1002/advs.201700870

105. A. Shahzad, K. Rasool, M. Nawaz, W. Miran, J. Jang et al., Heterostructural $\mathrm{TiO}_{2} / \mathrm{Ti}_{3} \mathrm{C}_{2} \mathrm{~T}_{x}$ (MXene) for photocatalytic degradation of antiepileptic drug carbamazepine. Chem. Eng. J. 349, 748-755 (2018). https://doi.org/10.1016/j. cej.2018.05.148
106. Y. Li, Z. Yin, G. Ji, Z. Liang, Y. Xue et al., 2D/2D/2D heterojunction of $\mathrm{Ti}_{3} \mathrm{C}_{2} \mathrm{MXene} / \mathrm{MoS}_{2}$ nanosheets/ $/ \mathrm{TiO}_{2}$ nanosheets with exposed (001) facets toward enhanced photocatalytic hydrogen production activity. Appl. Catal. B 246, 12-20 (2019). https://doi.org/10.1016/j.apcatb.2019.01.051

107. C.J. Zhang, S. Pinilla, N. McEvoy, C.P. Cullen, B. Anasori et al., Oxidation stability of colloidal two-dimensional titanium carbides (MXenes). Chem. Mater. 29, 4848-4856 (2017). https://doi.org/10.1021/acs.chemmater.7b00745

108. M. Sharma, S. Vaidya, A.K. Ganguli, Enhanced photocatalytic activity of $\mathrm{g}-\mathrm{C}_{3} \mathrm{~N}_{4}-\mathrm{TiO}_{2}$ nanocomposites for degradation of Rhodamine B dye. J. Photochem. Photobiol. A 335, 287-293 (2017). https://doi.org/10.1016/j.jphotochem .2016 .12 .002

109. L.T. Alameda, P. Moradifar, Z.P. Metzger, N. Alem, R.E. Schaak, Topochemical deintercalation of Al from MoAlB: stepwise etching pathway, layered intergrowth structures, and two-dimensional MBene. J. Am. Chem. Soc. 140, 8833-8840 (2018). https://doi.org/10.1021/jacs.8b04705 